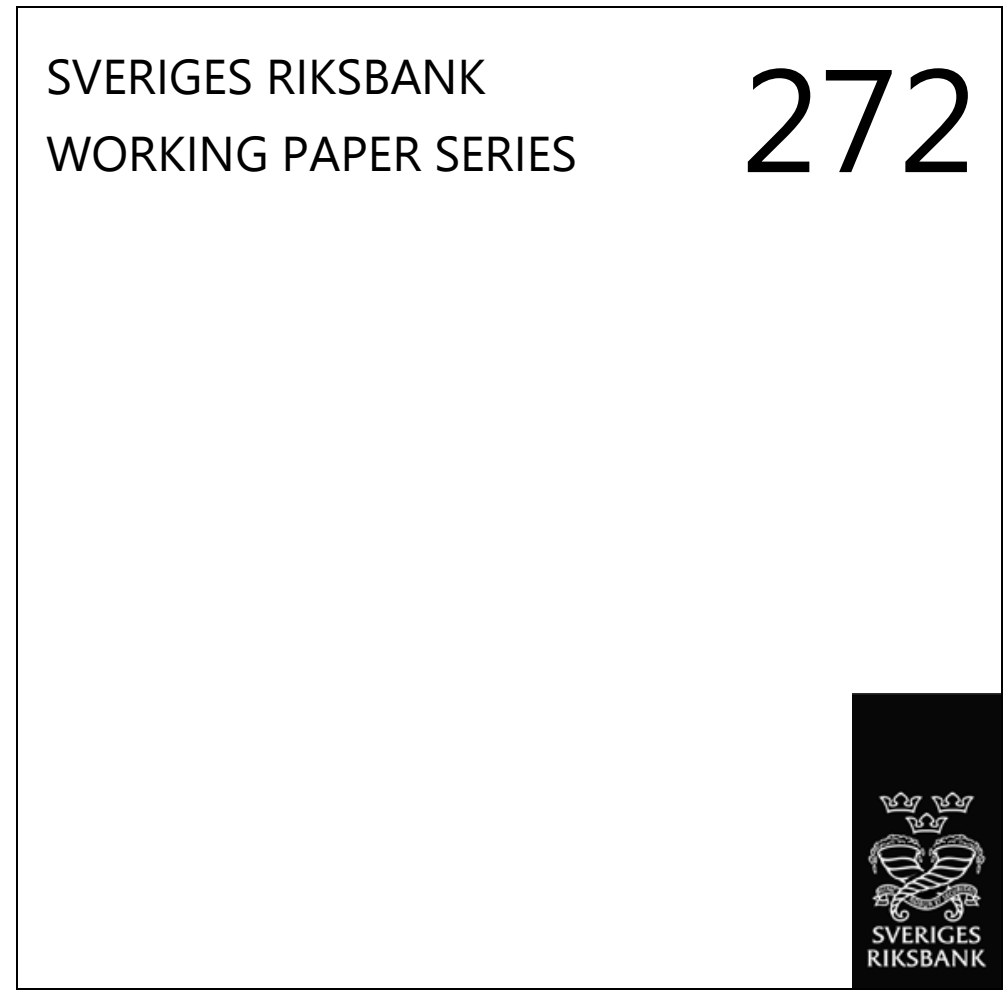

\title{
Housing Choices and Labor Income Risk
}

Thomas Jansson

August 2013 


\section{WORKING PAPERS ARE OBTAINABLE FROM}

Sveriges Riksbank • Information Riksbank • SE-103 37 Stockholm

Fax international: +4687870526

Telephone international: +4687870100

E-mail: info@riksbank.se

The Working Paper series presents reports on matters in the sphere of activities of the Riksbank that are considered to be of interest to a wider public.

The papers are to be regarded as reports on ongoing studies and the authors will be pleased to receive comments.

The views expressed in Working Papers are solely the responsibility of the authors and should not to be interpreted as reflecting the views of the Executive Board of Sveriges Riksbank. 


\title{
Housing Choices and Labor Income Risk
}

\author{
Thomas Jansson* \\ Sveriges Riksbank Working Paper Series No. 272
}

August 2013

\begin{abstract}
I show that individuals whose unemployment risk tends to increase more when local home prices fall optimally invest less in owner-occupied housing. Using a unique, Swedish register-based database, I find that a one standard deviation increase in the covariance between individually estimated unemployment risks and local home prices implies an average increase in the value of households' investments in owner-occupied housing of USD 13,300. Further, I find, in line with the predictions of my theoretical model, that same-industry couples rent more often, but, conditional on ownership, invest USD 9,200 more on average in single-family homes than different-industry couples.
\end{abstract}

JEL classifications: D12, D14, R21

Keywords: homeownership, housing demand, unemployment, house price risk

\footnotetext{
*Sveriges Riksbank. Correspondence to the author: Research Division, SE-103 37 Stockholm, Sweden. Email: thomas.jansson@riksbank.se. Phone: +46 87870469 . This paper is a revised version of the first chapter of my thesis at the Stockholm School of Economics. This work was supported by Bankforskningsinstitutet. I would especially like to thank Peter Englund, Todd Sinai, Paolo Sodini, Yannis M. Ioannides, Kasper Roszbach, Christian Friedrich, Tore Ellingsen, and seminar participants at UC Berkeley, Copenhagen Business School, University of Amsterdam, University of Helsinki, University of Maastricht, Stockholm School of Economics, SIFR, Finnish Economic Society Meeting 2011, the Philadelphia Fed, PHF-SAVE, and Sveriges Riksbank for their many helpful comments. All errors, however, are mine. The views expressed in this paper are solely the responsibility of the author and should not be interpreted as reflecting the views of the Executive Board of Sveriges Riksbank.
} 


\section{Introduction}

A household's decision to own or rent its home is not only a consumption issue but it also significantly affects the composition of the household's portfolio of risky assets. This dual role of housing as both a consumption and an investment good is emphasized in numerous papers, for example, Henderson and Ioannides (1983), Flavin and Yamashita (2002) and Cocco (2005). The housing consumption demand creates a highly leveraged position in real estate, especially for younger households. As a consequence, in most countries housing is the most important household asset. For example, in Sweden real estate holdings accounted for almost $70 \%$ of the total value of household assets in 2003, up from $56 \%$ just four years earlier (see Table 1). Owner-occupied single-family homes alone accounted for almost $42 \%$ of total household assets, while only $7 \%$ were invested in directly held stocks and $9 \%$ in mutual funds.

\section{Table 1}

Meanwhile, labor income is the main source of income for the vast majority of households. Labor income cannot, however, be capitalized, which generates an uninsurable background risk (see Heaton and Lucas, 2000). Hence, rational households are expected to incorporate labor income risk in their housing investment decisions. In fact, human capital and its covariance with the returns of assets should be accounted for in all investment decisions, not only when deciding how much to invest in owner-occupied housing. ${ }^{1}$ The way human capital affects households' willingness to hold specific assets has, in turn, important asset pricing implications.

As pointed out in Carroll, Dynan, and Krane (2003), measures of income volatility may be poor proxies of labor income risk since they usually include large controllable elements. Shocks to employment are, on the other hand, more exogenously driven, and may be a

\footnotetext{
${ }^{1}$ Betermier et al. (2012) find that households use financial assets to hedge labor income risk.
} 
better proxy of income uncertainty. ${ }^{2}$ The basic idea of this paper is that if there is a negative covariance between the returns to owner-occupied housing and the risk of becoming unemployed, the housing asset becomes riskier for households to hold. ${ }^{3}$ In other words, if the value of the house tends to fall at the same time as the risk of unemployment increases, it is more risky to hold the housing asset. Since the covariance between the returns to owner-occupied housing and the risk of becoming unemployed varies in the cross-section, households should put different weights on this risk in their housing investment decisions. Hence, in the data we expect to find a positive relationship between households' investments in owner-occupied housing and the covariance between individual unemployment risks and returns to owner-occupied housing.

In addition, by considering all household members, an important economic question that can be analyzed within my framework is whether higher unemployment risk correlation within the household, which increases household labor income risk, actually induces lower housing consumption. Since the covariance between the returns to owner-occupied housing and the risk of becoming unemployed should affect the housing investment decision, a straightforward implication of my theoretical model is that married couples in which both spouses work in the same industry (or share the same occupation) are expected to actually invest more on average in owner-occupied housing, conditional on ownership, than couples in which the spouses work in different industries (or hold different occupations).

The basic intuition why same-industry couples are expected to invest more on average in owner-occupied housing, conditional on ownership, is that the probability that both spouses' covariance values between their individual unemployment risks and returns to owner-occupied housing are in the upper tail of the distribution of covariance values in

\footnotetext{
${ }^{2}$ In fact, Shore and Sinai (2010) and Gathergood (2011) use unemployment risk as a measure of labor income risk.

${ }^{3}$ Note that a negative covariance between returns to owner-occupied housing and the risk of becoming unemployed implies a positive covariance between returns to owner-occupied housing and labor income, ceteris paribus.
} 
the population is higher for same-industry couples than it is for different-industry couples. Since a high value of the covariance between individual unemployment risks and returns to owner-occupied housing induces a larger optimal investment in owner-occupied housing, same-industry couples are expected to invest more in housing.

That being said, the probability that both spouses' covariance values between their individual unemployment risks and returns to owner-occupied housing are in the lower tail of the distribution of covariance values in the population is also higher for same-industry couples than it is for different-industry couples, which induces same-industry couples to rent more often than different-industry couples. Hence, the probability of homeownership is expected to be lower for same-industry couples than for different-industry couples. These mechanisms are described in more detail in Section 3.1.

In order to estimate individual values of the covariance between unemployment risks and returns to owner-occupied homes, I use 19 years of annual individual-level micro data from a unique, Swedish register-based dataset on employment and real estate holdings. In addition, I use single-family home price indices at the municipality (city) level to proxy returns to individual owner-occupied homes.

In the first step, I use the micro data to estimate time series of annual individual unemployment risks, which are shown to vary over time and depend on individual characteristics such as age, education, region of residence, gender, marital status, industry, sector and country of birth. ${ }^{4}$ In the second step, I use the time series of individual-level unemployment risks and the house price indices to estimate individual values of the covariance between the individually estimated annual unemployment risks and the returns to local single-family homes.

\footnotetext{
${ }^{4} \mathrm{My}$ estimations confirm that unemployment risk is indeed inescapable for most Swedish households and, hence, that Swedish employment protection legislation is not as strict as one may think. As pointed out by Massa and Simonov (2006), the Swedish labor market is actually quite similar to that of the United States in terms of companies' freedom to reduce their workforces in the event of work shortage. In fact, the shortest termination notice period in Europe is found in Sweden. In addition, public unemployment benefits are capped at a relatively low level in Sweden, increasing the financial consequences of unemployment for middle- and high-income individuals (see more in Section 4.2.2).
} 
On average, I find a negative covariance of -0.00084 (correlation of -0.5 ) in the data. There is, however, considerable variation in the cross-section.

The findings of my empirical analysis strongly indicate that there is, in line with the theoretical predictions, a significant positive relationship between investments in owner-occupied housing and the individually estimated values of the covariance between unemployment risks and returns to local single-family homes. I show that the probability of homeownership as well as the average investment in owner-occupied housing, conditional on ownership, are significantly lower for households with large negative covariance values. The results are robust to different model specifications. To summarize, a one standard deviation increase in the unemployment-home price covariance implies an average increase in the investment in owner-occupied housing of approximately SEK 96,000 (USD 13,300) ${ }^{5}$.

I find the largest effects of unemployment-home price covariance risk on investments in owner-occupied housing among high-income households, which is consistent with the conditions of the Swedish public unemployment benefit schemes, among highly educated households, and among households with short expected investment horizons. A possibility though is that borrowing constraints are imposed by banks and other credit institutions on households with large negative covariance values between individual unemployment risks and returns to local single-family homes. In other words, the empirical results might be driven by lender policies and not by individual household decisions. However, I find similar results for homeowners with very low absolute levels of debt.

Further, I find, in line with the theoretical predictions, that same-industry couples invest SEK 66,727 (USD 9,200) more on average in single-family homes, conditional on ownership, than different-industry couples, ceteris paribus. On the other hand, the expected probability of homeownership is 1 percentage point lower for a same-industry couple than it is for a different-industry couple.

\footnotetext{
${ }^{5}$ The exchange rate at the end of 2003 was 7.275 SEK/USD.
} 
The remainder of the paper is structured as follows. Section 2 reviews related literature, Section 3 outlines the theoretical framework, Section 4 describes the data and the methodological framework, Section 5 presents the main results and Section 6 concludes.

\section{Related Literature}

There is an extensive theoretical and empirical literature on factors influencing households' tenure choice and conditional demand for housing, although only a few papers explicitly consider the interaction between house price risk and various background risks, such as labor income risk. Furthermore, a growing literature treats the consequences of various consumption commitments. The traditional view is that increased labor income risk leads to lower consumption and higher precautionary savings. These models, however, generally assume that the current consumption level can be changed without a cost while, in fact, large costs are incurred by changing, for example, a household's current housing consumption.

Haurin (1991) shows that a 10\% increase in intertemporal variability of income reduces homeownership by the same amount as a 5\% decrease in income. Gathergood (2011) finds that unemployment risk lowers the likelihood of a home purchase. Expected house price risk also reduces demand for housing, as shown by Turner (2003); a one standard deviation increase in anticipated house price volatility corresponds to a $7 \%$ decline in housing demand.

Even though there seem to be significant economic gains for homeowners to hedge their exposure to house price risk through index-based real estate derivatives (see Case, Shiller, and Weiss, 1993), such derivative markets have not been successful in practice. Sinai and Souleles (2005) point out, however, that the notion that homeownership is very risky ignores the fact that the alternative to owning, i.e., renting, is also risky. In other words, owning a house introduces house price risk but in turn provides a hedge against fluctuations in future housing costs. The net risk of owning declines with a household's expected investment 
horizon and with the correlation between current and future housing costs.

One of the few papers that considers the implications of the covariance between labor income and home prices or rents on portfolio choice is Ortalo-Magné and Rady (2002). In a dynamic model in which future incomes, home prices and rents are uncertain, they show that the lower the covariance between household income and rents, the more likely the household is to buy. Tenure choice is also found to be affected by the investment horizon; if a household expects to live in its current home for an extended period of time, or if the covariance between the user cost of a household's current home and future potential homes is high, the household is more likely to become a homeowner.

Cocco (2005) and Yao and Zhang (2005) explicitly consider the impact of the covariance between home prices and labor income on portfolio choice. However, both papers use a single population variance-covariance matrix. The first paper to interact home prices and labor income at a disaggregated level is Davidoff (2006), who demonstrates that U.S. households working in industries in which aggregate labor income strongly covaries with local home prices are less inclined to become homeowners, and when they do make a purchase, choose to buy a less expensive home.

Finally, Shore and Sinai (2010) demonstrate that if only one spouse in a married couple is unemployed, it may be optimal for the household, under certain assumptions, to stay in its current home and reduce its consumption of other goods due to high transaction and moving costs. If both spouses are concurrently unemployed, however, the household is more likely to pay the transaction and moving costs and reduce its housing consumption by moving to a smaller house. An implication of their model is that spouses whose unemployment risks are highly correlated, for example if they share the same occupation or work in the same industry, may actually invest more in owner-occupied housing, ex ante, than less correlated couples despite a higher household labor income risk.

In fact, their empirical findings indicate that home-owning couples in which the husband 
and wife share the same occupation invest at least $2.1 \%$ more in owner-occupied housing, on average, than couples not sharing the same occupation. Tenure choice is also affected; the probability of homeownership is somewhat lower for same-occupation couples than for different-occupation couples. In their analysis, however, Shore and Sinai do not consider the effects of the covariance between individual unemployment risks and local home prices on married couples' optimal investment in owner-occupied housing.

This paper extends the existing literature in a significant way by using high-quality register-based micro data to estimate the covariance between unemployment risks and local home prices at an individual level, and by considering the implications of, for example, investor sophistication or investment horizon on individuals' recognition and assessment of the unemployment-home price covariance risk. Further, as I show in a novel way in this paper, even without taking transaction and moving costs into account, same-industry (or same-occupation) couples are expected to rent their home more often and invest more on average in owner-occupied housing, conditional on ownership, than different-industry (or different-occupation) couples.

\section{Theoretical Framework}

The impact of labor income and house price risks on households' housing choices may be analyzed using a simple two-period partial equilibrium model in which utility is gained from housing services, $h$, and a numeraire, $x$ (consumption of other goods). The basic theoretical framework follows that of Davidoff (2006), but is modified in two dimensions. The first modification of the model is that labor income fluctuations are driven by changes in unemployment risk. The second modification of the model is that not only the head of the household is considered, but all household members. By including all household members, an important economic question that can be analyzed within this framework is whether 
higher unemployment risk correlation within the household, which increases household labor income risk, may induce an increase in optimal housing consumption.

The model shows that the probability of becoming a homeowner as well as the optimal investment in owner-occupied housing increase with the covariance between individual unemployment risks and returns to owner-occupied housing, all else equal. The model also shows, in a novel way, that dual-earning married couples in which the spouses share the same occupation or work in the same industry (and hence face highly correlated unemployment risks and a more volatile second-period household income), may actually invest more in owner-occupied housing conditional on ownership than couples in which the spouses do not share the same occupation or work in different industries. The probability of homeownership, on the other hand, is somewhat lower for couples in which the spouses share the same occupation or work in the same industry.

\subsection{Model}

I use a simple two-period partial equilibrium model in which utility is gained from housing services, $h$, and a numeraire, $x$. I assume an incomplete market where renters own no housing and homeowners own exactly as much housing as they consume. The interest rate, $r$, is non-stochastic and saving and lending are assumed to be riskless. Labor supply is fixed. ${ }^{6} \mathrm{~A}$ household consists of $n$ members. Households maximize expected utility by choosing optimal levels of housing services, $h$, and savings, $S$ :

$$
\max _{h, S} U=u(h, x)+E v(W),
$$

where $u(x, h)$ is the utility derived from consumption of housing, $h$, and other goods, $x$, and $v(W)$ is the indirect utility derived from second-period wealth, $W . u$ and $v$ are assumed to

\footnotetext{
${ }^{6}$ Bodie, Merton and Samuelson (1992) study the effect of flexible labor supply on portfolio choice.
} 
be increasing and strictly quasi concave.

In the first period, a household receives a non-stochastic labor income, $y_{k, 1}$, from each household member $k$ and decides how much to save, $S$, the optimal quantity of housing to consume, $h$, and whether to own or rent. If a household finds it optimal to rent, it pays $h R_{1}$ for its housing consumption in the first period and its budget constraint equals:

$$
\sum_{k=1}^{n} y_{k, 1}=x+h R_{1}+S .
$$

If the household instead finds it optimal to own, it pays $h \pi_{1}$ to buy its home and its budget constraint equals:

$$
\sum_{k=1}^{n} y_{k, 1}=x+h \pi_{1}+S .
$$

Second-period labor income, $\tilde{y}_{2}$, and home prices, $\tilde{\pi}_{2}$, are stochastic. A homeowner sells its home in the second period and receives an amount of $h \tilde{\pi}_{2}$. In line with previous literature, housing demand in the second period is set at a fixed level (set to zero for simplification).

Further, in the second period household member $k$ is employed with a probability of $\left(1-\tilde{p}_{k, 2}\right)$ and receives a wage of $w_{k, 2}$. With a probability of $\tilde{p}_{k, 2}$ household member $k$ is instead unemployed and receives unemployment benefits of $\alpha_{k} w_{k, 2}$, where $0 \leq \alpha_{k}<1$. Expected second-period income of household member $k, E\left(\tilde{y}_{k, 2}\right)$, then equals $E\left(w_{k, 2}\left(1-\tilde{p}_{k, 2}\left(1-\alpha_{k}\right)\right){ }^{7}\right.$ That is, expected income decreases with the expected individual unemployment probability, $E\left(\tilde{p}_{k, 2}\right)$, and increases with the unemployment benefit level, $\alpha$. To summarize, second period

\footnotetext{
${ }^{7}$ I would obtain similar results if I assume that wages and unemployment risk are negatively correlated. A simple way to model that is $w_{k, 2}=w_{k, 2}^{0}\left(1-\hat{\beta}_{k} \tilde{p}_{k, 2}\right)$, where $\hat{\beta}_{k}=\beta_{k} /\left(1-\tilde{p}_{k, 2}\left(1-\alpha_{k}\right)\right)$ and $w_{k, 2}^{0}$ equals the wage when $\tilde{p}_{k, 2}=0$. That is, wages are assumed to decrease with unemployment risk by a rate of approximately $\beta_{k}$. Expected second-period income, $E\left(\tilde{y}_{k, 2}\right)$, then equals $E\left(w_{k, 2}\left(1-\tilde{p}_{k, 2}\left(1-\alpha_{k}+\beta_{k}\right)\right)\right.$. As an empirical fact, wages in Sweden are relatively unaffected by prevailing unemployment rates (see Section 4.2.2).
} 
wealth, $W$, of a home-owning household equals:

$$
W=\left(\sum_{k=1}^{n} \tilde{y}_{k, 2}\right)+h \tilde{\pi}_{2}+(1+r) S
$$

and second period wealth of a renter equals:

$$
W=\left(\sum_{k=1}^{n} \tilde{y}_{k, 2}\right)+(1+r) S .
$$

To find out how the covariance between individual unemployment risks and home prices affects optimal housing investment in this model, I use the fact that Davidoff (2006) shows that:

$$
\operatorname{sign}\left(\frac{d h}{d \theta}\right)=\operatorname{sign}\left(U_{h \theta}-\frac{U_{S h} U_{S \theta}}{U_{S S}}\right)
$$

where $\theta$ is a specific parameter of the joint distribution of home prices and income. Hence, in the simplest case, optimal investment in owner-occupied housing, $h$, will increase with $\theta$ if the second derivative $U_{h \theta}$ is positive and the second derivative $U_{S \theta}$ is zero everywhere.

These two conditions are fulfilled if we assume mean-variance utility and that the housing consumption in the second period is zero. ${ }^{8}$ Under these assumptions, expected indirect utility derived from second-period wealth, $W$, equals:

$$
E v(W)=a(E(W))+b(\operatorname{Var}(W))
$$

where $a^{\prime}>0$ and $b^{\prime}<0$.

If $w_{2}$ and $\alpha$ are assumed to be deterministic, the variance of second-period wealth of a

\footnotetext{
${ }^{8}$ See Davidoff (2006) for a more detailed analysis of these assumptions.
} 
home-owning household can be expressed as follows:

$$
\begin{aligned}
\operatorname{Var}(W) & =\operatorname{Var}\left(\sum_{k=1}^{n} \tilde{y}_{k, 2}\right)+2 \operatorname{Cov}\left(\sum_{k=1}^{n} \tilde{y}_{k, 2}, h \tilde{\pi}_{2}\right)+\operatorname{Var}\left(h \tilde{\pi}_{2}\right) \\
& =\operatorname{Var}\left(\sum_{k=1}^{n} \tilde{y}_{k, 2}\right)-2 h \operatorname{Cov}(\tilde{p}, \tilde{\pi})^{h}+h^{2} \operatorname{Var}\left(\tilde{\pi}_{2}\right),
\end{aligned}
$$

where $\operatorname{Cov}(\tilde{p}, \tilde{\pi})^{h}=\sum_{k=1}^{n}\left(1-\alpha_{k}\right) w_{k, 2} \operatorname{Cov}\left(\tilde{p}_{k, 2}, \tilde{\pi}_{2}\right)$. In other words, the variance of second period wealth of a home-owning household increases with the variance of labor income and with the variance of home prices, and decreases with the household covariance between individual unemployment risks and home prices, $\operatorname{Cov}(\tilde{p}, \tilde{\pi})^{h}$.

Then, since first period utility and expected second period wealth is unaffected by the covariance between unemployment risks and home prices, we get a positive relationship between investment in housing and $\operatorname{Cov}(\tilde{p}, \tilde{\pi})^{h}$ from equation $(2)$ :

$$
\begin{aligned}
\operatorname{sign}\left(\frac{d h}{d \operatorname{Cov}(\tilde{p}, \tilde{\pi})^{h}}\right) & =\operatorname{sign}\left(U_{h \operatorname{Cov}(\tilde{p}, \tilde{\pi})^{h}}-\frac{U_{S h} U_{S \operatorname{Cov}(\tilde{p}, \tilde{\pi})^{h}}}{U_{S S}}\right) \\
& =\operatorname{sign}\left[b^{\prime}\left(\frac{\partial^{2} \operatorname{Var}(W)}{\partial h \partial \operatorname{Cov}(\tilde{p}, \tilde{\pi})^{h}}\right)-0\right] \\
& =\operatorname{sign}\left(-2 b^{\prime}\right)>0 .
\end{aligned}
$$

Proposition 1 Under the assumptions of mean-variance expected utility and a fixed level of housing consumption in the second period, a household's optimal investment in owneroccupied housing increases with the second-period unemployment risk-home price covariance, $\operatorname{Cov}(\tilde{p}, \tilde{\pi})^{h}$. If $\operatorname{Cov}(\tilde{p}, \tilde{\pi})^{h}$ falls below a certain level, $\overline{\operatorname{Cov}(\tilde{p}, \tilde{\pi})^{h}}$, renting is preferable to owning.

Proof. See above.

Proposition 1 implies two testable hypotheses: 
H1: A household's probability of homeownership increases with the household-specific covariance between individual unemployment risks and local home prices, ceteris paribus.

H2: A household's optimal investment in owner-occupied housing increases with the householdspecific covariance between individual unemployment risks and local home prices, ceteris paribus.

Proposition 1 and Hypotheses 1 and 2 apply to households of all sizes. If a household consists of more than one wage earner, though, an important economic question is whether its housing investment decision is affected by the magnitude of the correlations between the unemployment risks of individual household members. The implications of this issue, with a focus on dual-earning married couples, are analyzed next. The same principles apply, however, to all multiple-earning households.

An important fact is that the variance of second-period household income increases with the correlation of the spouses' unemployment risks, all else equal (see Equation (4)). A high unemployment risk correlation (for example, if the spouses share the same occupation or work in the same industry) should hence have a negative effect on married couples' willingness to invest in housing. Interestingly, there is another effect of sharing the same occupation or working in the same industry that has opposite implications on the household housing investment decision. This effect follows directly from the theoretical model outlined above. Basically, if the spouses work in different industries (or hold different occupations), there is a "diversification" effect to $\operatorname{Cov}(\tilde{p}, \tilde{\pi})^{h},{ }^{9}$ which means that a large fraction of differentindustry couples will have a value of $\operatorname{Cov}(\tilde{p}, \tilde{\pi})^{h}$ around the distribution mean. ${ }^{10}$ Hence, from Proposition 1 it follows that most different-industry couples will enter the housing

\footnotetext{
${ }^{9}$ Remember that $\operatorname{Cov}(\tilde{p}, \tilde{\pi})^{h}=\sum_{k=1}^{2}\left(1-\alpha_{k}\right) w_{k, 2} \operatorname{Cov}\left(\tilde{p}_{k, 2}, \tilde{\pi}_{2}\right)$.

${ }^{10}$ One way to think of this is that a low correlation generates a risk-reducing "diversification" effect, comparable to holding two less correlated instead of two highly correlated stocks.
} 
market and buy medium-sized houses, all else equal.

On the other hand, a larger share of spouses who share the same occupation or work in the same industry have either a low or a high value of $\operatorname{Cov}(\tilde{p}, \tilde{\pi})^{h}$. In other words, in the population of same-industry (or same-occupation) couples the distribution of $\operatorname{Cov}(\tilde{p}, \tilde{\pi})^{h}$ values is more dispersed, i.e., the variance is higher. From the theoretical model we know that the distribution of $\operatorname{Cov}(\tilde{p}, \tilde{\pi})^{h}$ is truncated, i.e., below a certain value, $\overline{\operatorname{Cov}(\tilde{p}, \tilde{\pi})^{h}}$, the household is better off renting. Under some basic assumptions, this means that a smaller fraction of same-industry couples will buy, but at the same time, conditional on ownership, same-industry couples will buy more expensive homes since they will have a higher value of $\operatorname{Cov}(\tilde{p}, \tilde{\pi})^{h}$ on average conditional on $\operatorname{Cov}(\tilde{p}, \tilde{\pi})^{h}$ being above the truncation value.

The general case is illustrated in Figure 1, which shows the distributions of $\operatorname{Cov}(\tilde{p}, \tilde{\pi})^{h}$ for same- and different-industry couples (where I assume normal distributions and that $\left.\overline{\operatorname{Cov}(\tilde{p}, \tilde{\pi})^{h}}<E\left(\operatorname{Cov}(\tilde{p}, \tilde{\pi})^{h}\right)\right)$. If the correlation between $\operatorname{Cov}\left(\tilde{p}_{1,2}, \tilde{\pi}_{2}\right)$ and $\operatorname{Cov}\left(\tilde{p}_{2,2}, \tilde{\pi}_{2}\right)$ is higher for same-industry couples than for different-industry couples, the distribution of $\operatorname{Cov}(\tilde{p}, \tilde{\pi})^{h}$ values has a larger variance for same-industry couples. Since the distribution is truncated at $\overline{\operatorname{Cov}(\tilde{p}, \tilde{\pi})^{h}}$, we obtain the results that $E\left(\operatorname{Cov}(\tilde{p}, \tilde{\pi})^{h} \mid\right.$ owner $)$ and the probability of renting are higher for same-industry couples than for different-industry couples. The magnitude of these differences between same- and different-industry couples depends on the mean and the variance of $\operatorname{Cov}(\tilde{p}, \tilde{\pi})^{h}$ in the total population given a certain truncation value. These arguments are formalized in Proposition 2 and are proved in Appendix A.1.

[Figure 1]

Proposition 2 If $\operatorname{Cov}(\tilde{p}, \tilde{\pi})$ is normally distributed, the truncation value $\overline{\operatorname{Cov}(\tilde{p}, \tilde{\pi})^{h}}$ is below $E\left(\operatorname{Cov}(\tilde{p}, \tilde{\pi})^{h}\right)$, and there are two groups of married couples; one group with low correlation and one group with high correlation between $\operatorname{Cov}\left(\tilde{p}_{1,2}, \tilde{\pi}_{2}\right)$ and $\operatorname{Cov}\left(\tilde{p}_{2,2}, \tilde{\pi}_{2}\right)$, then it follows 
that:

(i) $\operatorname{Pr}\left(\operatorname{Cov}(\tilde{p}, \tilde{\pi})^{h}<\overline{\operatorname{Cov}(\tilde{p}, \tilde{\pi})^{h}}\right)$ and $E\left(\operatorname{Cov}(\tilde{p}, \tilde{\pi})^{h} \mid \operatorname{Cov}(\tilde{p}, \tilde{\pi})^{h}>\overline{\operatorname{Cov}(\tilde{p}, \tilde{\pi})^{h}}\right)$ are higher in the population of married couples with high correlation between $\operatorname{Cov}\left(\tilde{p}_{1,2}, \tilde{\pi}_{2}\right)$ and $\operatorname{Cov}\left(\tilde{p}_{2,2}, \tilde{\pi}_{2}\right)$ than in the population of married couples with low correlation between $\operatorname{Cov}\left(\tilde{p}_{1,2}, \tilde{\pi}_{2}\right)$ and $\operatorname{Cov}\left(\tilde{p}_{2,2}, \tilde{\pi}_{2}\right)$, ceteris paribus.

(ii) The difference in $\operatorname{Pr}\left(\operatorname{Cov}(\tilde{p}, \tilde{\pi})^{h}<\overline{\operatorname{Cov}(\tilde{p}, \tilde{\pi})^{h}}\right)$ between low-and high-correlation couples increases with the mean and decreases with the variance of $\operatorname{Cov}(\tilde{p}, \tilde{\pi})^{h}$ in the total population. Under the additional assumption that 50-84\% of all households are homeowners, the difference in $E\left(\operatorname{Cov}(\tilde{p}, \tilde{\pi})^{h} \mid \operatorname{Cov}(\tilde{p}, \tilde{\pi})^{h}>\overline{\operatorname{Cov}(\tilde{p}, \tilde{\pi})^{h}}\right)$ between low-and high-correlation couples decreases with the mean and increases with the variance of $\operatorname{Cov}(\tilde{p}, \tilde{\pi})^{h}$ in the total population, ceteris paribus.

\section{Proof. See Appendix A.1.}

In Appendix A.1, I show that under the assumptions stated above $E\left(\operatorname{Cov}(\tilde{p}, \tilde{\pi})^{h} \mid\right.$ owner $)$ and the probability of renting increase with the standard deviation of $\operatorname{Cov}(\tilde{p}, \tilde{\pi})^{h}$ in the population. Since the standard deviation of $\operatorname{Cov}(\tilde{p}, \tilde{\pi})^{h}$ values is higher in the population of married couples with a high correlation between $\operatorname{Cov}\left(\tilde{p}_{1,2}, \tilde{\pi}_{2}\right)$ and $\operatorname{Cov}\left(\tilde{p}_{2,2}, \tilde{\pi}_{2}\right)$ than in the population of married couples with a low correlation between $\operatorname{Cov}\left(\tilde{p}_{1,2}, \tilde{\pi}_{2}\right)$ and $\operatorname{Cov}\left(\tilde{p}_{2,2}, \tilde{\pi}_{2}\right)$, high-correlation couples rent more often than low-correlation couples, all else equal. Further, since optimal investment in owner-occupied housing increases with $\operatorname{Cov}(\tilde{p}, \tilde{\pi})^{h}$ (see Proposition 1), I show that high-correlation couples invest more in owner-occupied housing on average, conditional on ownership, than low-correlation couples, all else equal.

Under the assumption that same-industry couples have a higher correlation between $\operatorname{Cov}\left(\tilde{p}_{1,2}, \tilde{\pi}_{2}\right)$ and $\operatorname{Cov}\left(\tilde{p}_{2,2}, \tilde{\pi}_{2}\right)$ than different-industry couples, Proposition 2 implies two testable hypotheses:

H3: $(i)$ The probability that a married couple has a value of $\operatorname{Cov}(\tilde{p}, \tilde{\pi})^{h}$ below the threshold 
level of $\overline{\operatorname{Cov}(\tilde{p}, \tilde{\pi})^{h}}$ and hence rents its home is larger if the spouses work in the same industry than if they work in different industries, ceteris paribus. (ii) The difference in rent probabilities between same- and different-industry couples increases with the mean and decreases with the variance of $\operatorname{Cov}(\tilde{p}, \tilde{\pi})^{h}$ values in the population, ceteris paribus.

H4: $(i)$ Conditional on ownership, a married couple has on average a higher value of $\operatorname{Cov}(\tilde{p}, \tilde{\pi})^{h}$ and thereby invests more in owner-occupied housing if the spouses work in the same industry than if they work in different industries, ceteris paribus. (ii) The differences in $\operatorname{Cov}(\tilde{p}, \tilde{\pi})^{h}$ and in housing investment, conditional on ownership, between same- and different-industry couples decreases with the mean and increases with the variance of $\operatorname{Cov}(\tilde{p}, \tilde{\pi})^{h}$ values in the population, ceteris paribus.

The intuition underlying Proposition 2 and Hypotheses 3 and 4 can be exemplified in the following simple way. Assume that there are two industries that only differ in one dimension. In one of the industries the covariance between unemployment risk and home prices is negative for all individuals working in that industry, $\operatorname{Cov}(\tilde{p}, \tilde{\pi})_{N}=-0.5$. In the other industry the covariance is positive, $\operatorname{Cov}(\tilde{p}, \tilde{\pi})_{P}=0.5$. For simplicity, $\left(1-\alpha_{k}\right) w_{k, 2}$ equals one for all individuals.

Assume that individuals are randomly assigned to one of the industries with equal probability. This means that in one out of four married couples, both spouses work in the negative covariance industry and $\operatorname{Cov}(\tilde{p}, \tilde{\pi})^{h}=\operatorname{Cov}\left(\tilde{p}_{1,2}, \tilde{\pi}_{2}\right)_{N}+\operatorname{Cov}\left(\tilde{p}_{2,2}, \tilde{\pi}_{2}\right)_{N}=-1$. Similarly, in one out of four couples, both spouses work in the positive covariance industry and $\operatorname{Cov}(\tilde{p}, \tilde{\pi})^{h}=1$. In the remaining 50 percent of all cases, the spouses work in different industries and $\operatorname{Cov}(\tilde{p}, \tilde{\pi})^{h}=0$. Assume further that $\overline{\operatorname{Cov}(\tilde{p}, \tilde{\pi})^{h}}=-0.25$, which means that all same-industry couples in the negative covariance industry prefer to rent and all sameindustry couples in the positive covariance industry prefer to buy. The different-industry 
couples also prefer to become homeowners. Hence, from this simple example we can draw the following conclusions, which are in line with Proposition 2:

$$
(\operatorname{Pr}(\text { renter } \mid \text { same ind. })=0.5)>(\operatorname{Pr}(\text { renter } \mid \text { diff. ind. })=0),
$$

and $E\left(\left(\operatorname{Cov}(\tilde{p}, \tilde{\pi})^{h} \mid\right.\right.$ owner \& same ind. $\left.)=1\right)>\left(E\left(\operatorname{Cov}(\tilde{p}, \tilde{\pi})^{h} \mid\right.\right.$ owner \& diff. ind. $\left.)=0\right)$.

Let us now increase the variance of $\operatorname{Cov}(\tilde{p}, \tilde{\pi})^{h}$ and decrease $E\left(\operatorname{Cov}(\tilde{p}, \tilde{\pi})^{h}\right)$ by assuming that $\operatorname{Cov}(\tilde{p}, \tilde{\pi})_{N}=-1$ and $\operatorname{Cov}(\tilde{p}, \tilde{\pi})_{P}=0.75$. As before, $\overline{\operatorname{Cov}(\tilde{p}, \tilde{\pi})^{h}}=-0.25$. In this case, for different-industry couples $\operatorname{Cov}(\tilde{p}, \tilde{\pi})^{h}=-0.25=\overline{\operatorname{Cov}(\tilde{p}, \tilde{\pi})^{h}}$. Therefore, assume that one half of the different-industry couples prefer to rent and one half of them prefer to buy. As before, all same-industry couples in the negative covariance industry prefer to rent and all same-industry couples in the positive covariance industry prefer to buy. From this simple example we obtain the following results:

$$
(\operatorname{Pr}(\text { renter } \mid \text { same ind. })=0.50)=(\operatorname{Pr}(\text { renter } \mid \text { diff. ind. })=0.50) \text {, }
$$

and $\left(E\left(\operatorname{Cov}(\tilde{p}, \tilde{\pi})^{h} \mid\right.\right.$ owner \& same ind. $\left.)=1.50\right)>\left(E\left(\operatorname{Cov}(\tilde{p}, \tilde{\pi})^{h} \mid\right.\right.$ owner \& diff. ind. $\left.)=-0.25\right)$.

To summarize, when we keep $\overline{\operatorname{Cov}(\tilde{p}, \tilde{\pi})^{h}}$ constant and decrease the mean and increase the variance of $\operatorname{Cov}(\tilde{p}, \tilde{\pi})$ in the population, the difference between $E\left(\operatorname{Cov}(\tilde{p}, \tilde{\pi})^{h} \mid\right.$ owner \& same ind.) and $E\left(\operatorname{Cov}(\tilde{p}, \tilde{\pi})^{h} \mid\right.$ owner \& diff. ind.) increases. We also notice that the difference in rent probabilities between same- and different-industry couples decreases (in this simple case the difference disappears altogether). 


\section{Data and Methodology}

\subsection{Micro Data}

I use a high-quality Swedish register-based longitudinal database denoted LINDA (Longitudinal INdividual DAta). ${ }^{11}$ LINDA includes annual cross-sectional samples of around 300,000 individuals, or approximately $3 \%$ of the entire Swedish population. Sampled individuals and their family members are tracked over time. The sampling procedure ensures that the panel is representative of the Swedish population as a whole and that each annual cohort is cross-sectionally representative. ${ }^{12}$

The principal source of data are the income registers, which are based on filed tax returns. ${ }^{13}$ The data include measures of income, government transfers, market values of real and financial assets, ${ }^{14}$ and individual characteristics such as sex, marital status, education, municipality of residence and country of birth. LINDA also contains various labor market variables, such as employment status, labor income, industry and sector of employment (referring to the main industry and sector of employment in a particular year) and unemployment insurance transfers.

In the empirical analysis, the 2003 wave of LINDA is used to evaluate households' investments in owner-occupied housing. Since interaction effects between unemployment risk and homeownership are less relevant for younger and older individuals, the sample is restricted to individuals aged 26-60. Owners of cooperative apartments (described in Section 4.2.1)

\footnotetext{
${ }^{11}$ LINDA is a joint project by Uppsala University, The National Social Insurance Board, Statistics Sweden and the Swedish Ministry of Finance. LINDA is described in more detail in Edin and Fredriksson (2000).

${ }^{12}$ However, since individuals and not households are sampled, large households tend to be overrepresented in the final sample.

${ }^{13}$ In the income registers, all variables are defined primarily for tax purposes. Consequently, income variables, for example, are contingent on the tax legislation in a specific year, and cohabitants with no children in common are usually coded as singles.

${ }^{14}$ The market values of real estate holdings are estimated by Statistics Sweden, which uses tax-assessed values and actual transaction prices in the surrounding areas. The market values of the financial assets are actual values and not estimates because banks and financial institutions in Sweden are required by law to report the market values of individual holdings.
} 
are excluded since there are no reliable sources of the true market value ${ }^{15}$ of such apartments and no price indices for cooperative apartments in Sweden covering the period of analysis. Sampled individuals who are self-employed, unemployed or report no labor income are also excluded.

The final sample of both single- and multiple-member households consists of 147,906 households. Homeowners are defined as households for whom the market value of owneroccupied housing is strictly positive. According to this definition, 97,936 of 147,906 households are classified as homeowners and the remainder are renters.

For the empirical analysis of married couples, the same sample selection criteria apply. However, this case includes only married couples (including same-sex couples) living together. Furthermore, if any spouse is unemployed or earns less than SEK 10,000 a year, that household is excluded. The final sample consists of 52,928 married couples, of which 45,205 are classified as homeowners.

The value of owner-occupied housing is defined as the aggregated market value of singlefamily homes owned by all members of the household. The average home value is SEK 867,851 (median SEK 645,280) for the whole sample, and, conditional on ownership, SEK 1,310,656 (median SEK 1,047,190) (see Table 2). Definitions and summary statistics of all other variables are provided in Appendix A.2 and in Tables 2 and 3. For the sample of both single- and multiple-member households, the characteristics of the member of the household with the highest reported disposable income are used to identify variables such as age and gender.

Table 2

\footnotetext{
${ }^{15}$ The "true" market value of a cooperative apartment must include the apartment's share of the association's debt holdings, since larger debts imply higher future fees and a lower transaction price, ceteris paribus.
} 
Table 3

\subsection{Institutional Setting}

\subsubsection{Housing Market}

The Swedish housing market can be divided into three main categories: owner-occupied single-family homes, cooperative apartments, and rental apartments. ${ }^{16}$ The largest categories are single-family home owners and renters, each constituting $40 \%$ of households. Owners of cooperative apartments account for $15 \%$ of households (see Table 4). Single-family homes and shares in cooperative housing associations are sold freely on the open market.

\section{Table 4}

A shareholder in a cooperative housing association possesses the right to use a specific apartment for an indefinite term. The property is owned and managed by the association, which may hold debt. To cover maintenance costs and interest payments, a monthly fee is paid by the shareholders.

More than $50 \%$ of the total number of rental apartments in Sweden is owned by nonprofit municipal housing companies competing directly with private landlords in both less popular suburbs and attractive inner-city locations (a "unitary market" system, as described in Kemeny, 1995). Although there is no formal rent control, rents charged by municipal companies act as a ceiling on rents in similar privately owned properties nearby (a maximum divergence of $4-5 \%$ is allowed). ${ }^{17}$

\footnotetext{
${ }^{16}$ As of 2009, condominiums are also available, but are still not very common.

${ }^{17}$ Rents in municipal housing companies are intended to cover management and maintenance expenses and to yield a fair return on invested capital; they are determined by negotiations with the local tenants' associations.
} 


\subsubsection{Labor Market}

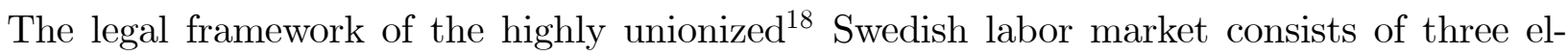
ements: labor legislation, collective centralized bargaining agreements, and individual employment agreements. There are no legal minimum wages, minimum wage levels in different sectors being imposed by collective bargaining agreements.

The wage structure of the Swedish labor market is downwardly rigid, mainly due to strict labor market policies and strong labor unions. ${ }^{19}$ According to the conditions of collective bargaining agreements, employers cannot, for example, unilaterally impose wage cuts, even after the agreement has expired. Actually, Sweden is shown to have the most widespread real wage rigidity of 16 countries in a study by Dickens et al. (2007). They find a significant linear relationship between real wage rigidity and union density. Sweden is in the upper righthand corner with the highest union density and the highest real wage rigidity encountered in the study. The relationship found between real wage rigidity and employment protection legislation, however, is very weak and insignificant. In fact, employment protection legislation is less strict in Sweden than in many other European countries. ${ }^{20}$

Further, Festing et al. (1999) conclude that employee stock ownership plans (ESOPs) and profit-sharing programs are less common in Sweden than in Germany, France, and the U.K. ${ }^{21}$ Hence, the main conclusion to be drawn from these empirical studies is that the

\footnotetext{
${ }^{18}$ In Sweden, approximately $85 \%$ of blue-collar workers and $75 \%$ of white-collar workers are unionized.

${ }^{19}$ Empirical evidence on this issue is presented by Agell and Bennmarker (2003). They show, on the one hand, that only $1.1 \%$ of Swedish employees actually received nominal wage cuts during the recession in the early 1990s, which is significantly fewer than in other countries experiencing similar crises. The unemployment rate, on the other hand, increased from $2.8 \%$ in 1990 to $13.6 \%$ in 1994. During this period, inflation was low and stable.

${ }^{20}$ As pointed out by Massa and Simonov (2006), the Swedish labor market is actually quite similar to that of the United States in terms of companies' freedom to reduce their workforces in the event of work shortage. In fact, the shortest termination notice period in Europe is found in Sweden.

${ }^{21}$ Only $7.1 \%$ of Swedish organizations offer ESOPs for managers compared to $30.5 \%$ of U.K. organizations (see Table A2). The percentage of Swedish organizations offering profit-sharing programs is higher than that of Swedish organizations offering ESOPs. Nonetheless, only 12-15\% of Swedish organizations offers such programs to different categories of personnel, which is a much smaller fraction than in the other studied countries.
} 
largest risk of involuntary reductions in real income faced by Swedish employees is that of unemployment and not of reductions in wages.

The Swedish Employment Protection Act states that employment contracts are valid for an indefinite term. Fixed-term contracts may, however, be entered into under certain circumstances stipulated in law. Notice of employee termination by the employer must be based on objective grounds, such as work shortage or gross neglect of obligations to the employer. Order of termination is determined based on employee seniority, employees with greater employment duration having priority over those with less (the "last-in, firstout principle"). Employees terminated because of work shortage have priority rights to re-employment in the company that previously employed them.

Public unemployment benefits in Sweden are funded by employer's fees, taxes, and, to a lesser degree, membership fees. The coverage rate is approximately $85 \%$ and received benefits are taxable income. From an international perspective, Swedish public unemployment benefits may initially seem relatively generous. ${ }^{22}$ Benefits are, however, capped at a relatively low income level. In short, Swedish unemployment benefits are comprised of three components:

1. A comprehensive public scheme providing a lower level of basic support: SEK 320 a day with a six-month minimum employment requirement;

2. A supplementary income-based public compensation scheme, applicable to members of an unemployment insurance fund who fulfill certain working conditions, ${ }^{23}$ provides

\footnotetext{
${ }^{22}$ Eligibility conditions, waiting periods, maximum durations, initial payment rates and coverage rates for Sweden, Germany and the United Kingdom are reported in Table A1.

${ }^{23}$ To be admitted to an unemployment insurance fund, the applicant must have been employed for a minimum of 17 hours per week in four of five consecutive weeks. The working conditions require the applicant to have been employed for a minimum of six months (for more than 70 hours per month) in the preceding year, or for at least 450 hours over a six-month period ( 45 hours per month). (Source: The Swedish Unemployment Insurance Board, IAF)
} 
compensation for $80 \%$ of previous earnings up to a maximum benefit of SEK $680^{24}$ per day for a maximum of 300 days (5-day week);

3. Supplementary private insurance providing compensation above the ceiling of the public schemes, offered by, for example, trade unions.

\subsection{Methodology}

This section describes the empirical methodology in more detail. In the first steps, time series of individual unemployment risks and local home prices are estimated. The final important step concerns the estimation of the covariance between unemployment risks and local home prices at an individual level.

\subsubsection{Estimation of Individual Unemployment Risks}

Individual unemployment risks are estimated annually from 1985 to 2003 using data from the LINDA database, described in Section 4.1. Only individuals between 26 and 60 years of age with strictly positive labor income are included in the sample; the self-employed are excluded. The sample size varies between 203,349 and 300,220 individuals annually.

An individual is classified as unemployed if he or she receives any public unemployment benefits in a specific year (the Swedish unemployment insurance system is described in more detail in Section 4.2.2). Explanatory variables included in the probit model are marital status, sector, industry, age group, gender, country of birth, A-region ${ }^{25}$ and education. ${ }^{26}$

Estimates from the annual probit regressions on unemployment are reported in Table 5 (for every third year). The coefficients are fairly robust over the years, but there is some

\footnotetext{
${ }^{24}$ However, for the first 100 days of a benefit period, the maximum amount is SEK 730 per day (equivalent to $80 \%$ of a monthly salary of SEK 20,075). (Source: The Swedish Unemployment Insurance Board, IAF)

${ }^{25}$ Sweden is divided into 70 "A-regions," i.e., local labor markets, by Statistics Sweden

${ }^{26}$ Education, however, is only reported in LINDA from 1991 and onwards. Thus, education levels and fields of study from 1985 to 1990 are approximated using 1991 values. However, if there is information that the graduation year was between 1985 (and so on) and 1991, the 1991 education level is reduced by one step.
} 
time variation. The unemployment rate peak in the early 1990s recession is obvious; the percentage of sampled individuals receiving any form of unemployment benefits increased from $5 \%$ in 1985 to $15 \%$ in 1994.

\section{Table 5}

Unemployment risk is significantly higher for women and unmarried individuals. Country of birth also plays an important role, as individuals born in Sweden face a significantly lower unemployment risk. The high unemployment rate among youth is also obvious in the data and, as expected, we observe large variations in unemployment risk across A-regions (estimates not reported), industries and sectors. On the one hand, the fishing industry and the hotel and restaurant industry are industries with high average unemployment risk. On the other hand, it is unsurprising that the central government sector is a relatively secure sector.

\subsubsection{Estimation of Local Home Prices}

Purchase prices and tax-assessed values of all transactions involving owner-occupied singlefamily homes in Sweden are readily available from public registers. To estimate local singlefamily home price indices, I use $K / T$ ratios, i.e., average ratios between purchase prices, $K$, and tax-assessed values, $T$, for single-family homes at the lowest possible level provided by Statistics Sweden, which is at the municipality level (corresponding to a city in the US). ${ }^{27}$ The same method is used by Statistics Sweden to estimate official house price indices at the national and regional levels. Unfortunately, there are no $K / T$ ratios or price indices for

\footnotetext{
${ }^{27}$ Since homes sold a certain year may not be a random sample of the total housing stock, and since the total housing stock composition may vary from year to year, the reported $K / T$ ratios are adjusted by Statistics Sweden. Further, as long as tax-assessed values remain constant over time and only purchase prices change, the calculation of local home price indices is straightforward. However, there have been several large adjustments to the overall level of tax-assessed values of owner-occupied single-family homes in Sweden, specifically in 1990, 1996, and 2003. Statistics Sweden, however, provides keys for how to adjust old $K / T$ ratios to be able to consistently compare $K / T$ ratios over time.
} 
cooperative apartments covering the period of analysis.

\subsubsection{Estimation of Covariance between Individual Unemployment Risks and Local Home Prices}

Using the unemployment probability estimates from the annual probit regressions described above, time series of individual unemployment risks, $\hat{p}_{i, 1985}-\hat{p}_{i, 2003}$, are estimated for each individual $i$ in the samples from the 2003 wave of the LINDA dataset. These individual annual unemployment risk estimates and data on local single-family home prices from Statistics Sweden are then used to estimate the covariance between individual unemployment risks, $p_{i}$, and local home prices, $\pi_{j}$, in municipality $j$ as follows:

$$
C \hat{o} v\left(\tilde{p}_{i}, \tilde{\pi}_{j}\right)=\sum_{t=1986}^{2003}\left[\left(\hat{p}_{i t}-\hat{p}_{i, t-1}\right)\left(\left(\frac{\pi_{j t}}{\pi_{j, t-1}}-1\right)-\hat{g}_{j}\right)\right] /(18-1)
$$

where

$$
\hat{g}_{j}=\sum_{t=1986}^{2003}\left[\left(\frac{\pi_{j t}}{\pi_{j, t-1}}-1\right) / 18\right] .
$$

For simplicity, in this estimation I assume unemployment risk of individual $i, p_{i}$, to evolve over time as a random walk (with no drift) ${ }^{28}$ and home prices in municipality $j$ at time $t$, $\pi_{j t}$, to be random walks with drift of $g_{j}$.

The distribution of individual covariance estimates, $C \hat{o} v(\tilde{p}, \tilde{\pi})$, for the household head (i.e., the member of the household with the highest reported disposable income) is reported in Table 6. As expected, most estimates are negative and the distribution is negatively skewed with a mean of -0.00084 and a median of -0.00063 .

Table 6 also reports summary statistics for different subsamples. In line with the theo-

\footnotetext{
${ }^{28}$ Since unemployment rates did not seem to revert to a mean value after temporary shocks, Blanchard and Summers (1986) raised the question of hysteresis, implying that employment shocks would have permanent, or at least very persistent, effects on future unemployment rates. If that is the case, unemployment rates are expected to possess the characteristics of a unit root process. Blanchard and Summers find, in fact, empirical evidence of a hysteresis effect in several European countries.
} 
Table 6

retical predictions (see Hypothesis 1), the average value of $C \hat{o} v(\tilde{p}, \tilde{\pi})$ for renters, -0.00116 , is almost twice the average value of $C \hat{o} v(\tilde{p}, \tilde{\pi})$ for homeowners, -0.00068 . This is the first indication that $C \hat{o} v(\tilde{p}, \tilde{\pi})$ seems to predict tenure choice in the data. By sector, the central government sector displays the least negative average covariance and the private sector the most negative average covariance. By industry, the least negative average covariance estimates are found for fishing (where it is actually positive), electricity, gas and water supply and public administration and defense (see Figure 2). In contrast, the most negative average covariance estimates are found in the real estate, renting and business activities industry (see Figure 2) and the construction and hotel and restaurant industries. However, even within a certain industry or sector there are large variations in the individual covariance estimates.

[Figure 2]

To simplify interpretation and comparisons, the correlation coefficients between individual unemployment risks and local home prices, $\operatorname{Côr}(\tilde{p}, \tilde{\pi})$, are also reported in Table 6 . The sample distribution of $\operatorname{Corr}(\tilde{p}, \tilde{\pi})$ is positively skewed, with a mean of -0.50 and a median of -0.53 . Actually, only a few percent of the observations are positive. Average correlation coefficients are more negative for renters than for owners. By sector, the central government sector displays the least negative average correlation coefficient $(-0.38)$. By industry, the least negative average correlation coefficients are found for the fishing (0.11), public administration and defense (-0.12) and agriculture, hunting and forestry (-0.22) industries. In contrast, the unemployment risk of employees in the real estate, renting and business activities industry is, as expected, most negatively correlated with local home prices, having an average correlation coefficient of -0.61 . 
In Table 7, average correlation coefficients are sorted into combinations of local labor markets ("A-regions") and industries. The group with the most negative average pairwise correlation coefficients is dominated by the real estate, renting and business activities industry, and the group with the largest average positive correlation coefficients is dominated by public administration and defense. This is in line with the empirical findings presented above.

\section{Table 7}

Finally, the correlation between spouses' estimates of $C \hat{o} v(\tilde{p}, \tilde{\pi})$ is significantly higher for couples in which both spouses work in the same industry and sector (that is, private sector and local and central government sectors) than it is for couples in which the husband and wife work in different industries and sectors; 0.723 versus 0.424 (see Table 8). Similar evidence is found for the correlations between spouses' estimated unemployment probabilities $(0.587$ versus 0.373$)$ and spouses' actual unemployment episodes (0.168 versus 0.074$)$.

Table 8

\section{Empirical Results}

In order to test Hypotheses 1 and 2 outlined in Section 3 empirically, the individually estimated covariance values between individual unemployment risks and local home prices are used in regressions on tenure choice (see Section 5.1) and on the value of households' investments in single-family homes (see Section 5.2). Further, in Section 5.3, Hypotheses 3 and 4 are tested using the sample of married couples. Finally, important issues, such as expected investment horizon, unemployment insurance benefit levels and investor financial sophistication, that might have important implications on households' risk assessments and housing investment decisions are investigated in detail in Section 5.4. 


\subsection{Tenure Choice}

In this section households' actual tenure choice in the data is studied in order to test the following hypothesis:

H1: A household's probability of homeownership increases with the household-specific covariance between individual unemployment risks and local home prices, ceteris paribus.

As a first basic empirical test of Hypothesis 1, all sampled households are categorized in Table 9 according to the average home value in their municipality of residence ${ }^{29}$ and by $C \hat{o} v(\tilde{p}, \tilde{\pi})$ of the household head (i.e., the household member with the highest reported disposable income). As one might expect, the probability of being a homeowner decreases with the general price level of single-family homes and increases with household disposable income. More importantly, we observe, in line with the prediction of Hypothesis 1, that the probability of homeownership is higher for above-median-covariance households than it is for below-median-covariance households in all home price intervals and income quartiles.

\section{Table 9}

Formal probit regressions on tenure choice are presented next. First, the sample consisting of both single- and multiple-member households, described in Section 4.1, is used to run the following probit model:

$$
\text { homeowner }_{i}=\alpha+z_{i}^{\prime} \theta+e_{i},
$$

where homeowner indicates ownership of a single-family home and $z$ is a vector of household and household head characteristics such as household disposable income, family size, municipality of residence, age, gender, marital status, country of birth, unemployment risk, and $\hat{y}_{h}(1-\hat{\alpha}) \operatorname{Cov}\left(\tilde{p}_{1}, \tilde{\pi}\right) . \hat{y}_{h}$ is household disposable income, $(1-\hat{\alpha})$ is a measure of financial

\footnotetext{
${ }^{29}$ In the first quartile, the average home value is below SEK 856,220, in the second between SEK 856,220 and SEK 1,228,677, and in the fourth above SEK 1,991,269.
} 
loss in case of unemployment, and $C \hat{o} v\left(\tilde{p}_{1}, \tilde{\pi}\right)$ is the covariance between unemployment risk, $\tilde{p}$, and local home prices, $\tilde{\pi}$, of the household head.

Second, a household perspective is taken in order to study tenure choice among married couples in the data. The sample restricted to married couples (see Section 4.1) is used to run the following probit model:

$$
\left(\text { homeowner }_{i} \mid \text { married }\right)=\alpha+x_{i}^{\prime} \theta+e_{i},
$$

where $x$ is a vector of both household characteristics, such as household size and municipality of residence, and of individual characteristics of each spouse $k$, e.g. industry, sector, income, age group, unemployment risk and $\hat{y}_{k}\left(1-\hat{\alpha}_{k}\right) C \hat{o} v\left(p_{k}, \pi\right)$.

Summary statistics and definitions of included variables are provided in Tables 2 and 3 and in Appendix A.2. A positive relationship between $\hat{y}(1-\hat{\alpha}) C \hat{o} v(\tilde{p}, \tilde{\pi})$ and homeownership is predicted in accordance with Hypothesis 1 . As a base case, $\hat{\alpha}^{30}$ is set to zero for all individuals.

The empirical results of regression (7) are presented in Table 10, specifications (1) and (2). As expected, the probability of homeownership increases with household size and age. Married couples and individuals born in Sweden are more likely to own, while individuals who changed their place of residence or marital status in the previous five years are less likely to be homeowners (estimates not reported). The individual unemployment risk in 2003 is found to have a negative effect on homeownership. The estimated coefficient on individual average

\footnotetext{
${ }^{30} \alpha$ is thought of as unemployment insurance benefits paid as a percentage of prior labor income. In the case of unemployment, $80 \%$ of previous labor income up to a monthly salary of SEK 20,075 is compensated for by the supplementary unemployment insurance scheme; in this income interval $\alpha$ equals 0.8 (see Section 4.2.2 for details). Above that threshold, however, no further compensation is provided by the public insurance scheme, so $\alpha$ decreases with income. Though $\alpha$ is assumed to be constant across all individuals, given a certain level of income, the financial loss in the case of unemployment is also affected by unemployment duration and private unemployment insurance holdings. Furthermore, not all individuals are in fact members of a public unemployment insurance fund. Hence, $\alpha=0$ is used for all households as a base case; however, the actual estimated values of $\alpha$ are considered in Section 5.4.5.
} 
unemployment risk from 1985 through 2003 is, though, contrary to expectations, positive (estimates not reported). However, important factors directly affecting unemployment risk, such as sector, industry, education and age, are already controlled for.

Table 10

Most importantly, in line with the predictions of Hypothesis 1, the estimated coefficient on the covariance between individual unemployment risks and local home prices, $\hat{y}_{h} C \hat{o} v\left(\tilde{p}_{1}, \tilde{\pi}\right)$, is positive and significant in specification (2), which includes income interaction effects. An increase of one standard deviation in $\hat{y}_{h} C \hat{o} v\left(\tilde{p}_{1}, \tilde{\pi}\right)$ increases the average probability of owning by approximately 3 percentage points using a linear approximation. ${ }^{31}$ In other words, a household whose unemployment risk tends to rise at the same time as local home prices tend to go down is shown to be less prone to own its home, ceteris paribus.

The empirical results of regression (8) using the sample of married couples are reported in Table 11, specification (1). The coefficient on $\hat{y}_{1} C \hat{o} v\left(\tilde{p}_{1}, \tilde{\pi}\right)$ of the spouse with the highest reported disposable income, spouse 1 , is positive and weakly significant with a marginal effect of around 0.000073 , which is slightly lower then when using the whole sample (see above). For the lower-income spouse, spouse 2 , however, the coefficient on $\hat{y}_{2} C \hat{o} v\left(\tilde{p}_{2}, \tilde{\pi}\right)$ is found to be small and insignificant.

\section{Table 11}

When estimating the individual-specific value of the covariance between individual unemployment risks and local home prices there might, however, be measurement errors. Due to temporary negative income shocks, e.g., sickness, parental leave or a reduction in the number of working hours to take care of children, the actual reported income may underestimate the normal income given employment during a single or a couple of years. Since the income

\footnotetext{
${ }^{31}$ The standard deviation of $\hat{y}_{h} C \hat{o} v\left(\tilde{p}_{1}, \tilde{\pi}\right)$ is 322 (see Table 2) and the estimated marginal effect of $\hat{y}_{h} \operatorname{Co} v\left(\tilde{p}_{1}, \tilde{\pi}\right)$ is 0.0000915 .
} 
of the lower-income spouse, $\hat{y}_{2}$, is more likely to be affected by temporary negative income shocks than $\hat{y}_{1}, \hat{y}_{2} C \hat{o} v\left(\tilde{p}_{2}, \tilde{\pi}\right)$ might be measured with larger errors and attenuation bias may hence explain the lack of empirical significance of $\hat{y}_{2} C \hat{o} v\left(\tilde{p}_{2}, \tilde{\pi}\right)$ in the regression analysis. ${ }^{32}$

An important issue in the context of tenure choice is the implication of the prevailing rent regulation in Sweden (see Section 4.2.1 for details), a question that is dealt with in Section 5.4.4 in some detail.

\subsection{Value of Households' Investments in Single-Family Homes}

The purpose of this section is to test whether the value of a household's investment in a single-family home increases with the covariance between individual unemployment risks and local home prices, as specified in Hypothesis 2:

H2: A household's optimal investment in owner-occupied housing increases with the householdspecific covariance between individual unemployment risks and local home prices, ceteris paribus.

As a first basic empirical test, all sampled households are categorized in Table 12 according to the average home value in their municipality of residence and by $C \hat{o} v(\tilde{p}, \tilde{\pi})$ of the household head. In line with the predictions of Hypothesis 2, the average value of investments

\footnotetext{
${ }^{32}$ In Sweden there is a cap on maximum benefit levels in various social security programs, such as paid parental leave, which generally makes the financial loss lower for a household if the dependent spouse stays at home. To find out whether the income of the lower-income spouse is more likely to be affected by temporary negative income shocks, I specify the income of spouse $k$ in 2003 as follows:

$$
y_{k, 2003}=\bar{y}_{k, 1997-2000}+\varepsilon_{k, 2003},
$$

where $\bar{y}$ is average annual real income 1997-2000, and $\varepsilon$ is an income shock. We expect spouse 2 to have been hit more often by a negative income shock than spouse 1. Further, we expect the average negative income shock to be larger for spouse 2 than for spouse 1 . These expectations are in fact verified by the data. I use 39,753 married couples for which I have income data from 1997. For spouse 1 , the mean of $\left(\frac{\varepsilon_{1,2003}}{y_{1,2003}}\right)$ is 0.13 and the variance of $\left(\frac{\varepsilon_{1,2003}}{y_{1,2003}}\right)$ is 0.47 . For spouse 2 , the mean of $\left(\frac{\varepsilon_{2,2003}}{y_{2,2003}}\right)$ is 0.08 and the variance of $\left(\frac{\varepsilon_{2,2003}}{y_{2,2003}}\right)$ is 1.10 .
} 
in single-family homes is significantly higher for above-median-covariance households than it is for below-median-covariance households in all home price intervals and income quartiles. The largest difference is found in municipalities where the average home value exceeds SEK $1,991,269$. In these municipalities, the average investment in single-family homes amounts to SEK 1,718,237 for above-median-covariance households and SEK 919,816 for below-mediancovariance households. Similar patterns are evident when conditioning on homeownership.

\section{Table 12}

Next, formal regressions on the value of households' investments in owner-occupied singlefamily homes are performed in order to test Hypothesis 2. The following OLS regressions, using the sample of both single- and multiple-member households (regressions (10) and (11)), and the sample restricted to home-owning married couples (regression (12)), are run:

$$
\begin{gathered}
\text { value }_{i}=\alpha+z_{i}^{\prime} \theta+e_{i}, \\
\left(\text { value }_{i} \mid \text { homeowner }\right)=\alpha+z_{i}^{\prime} \theta+e_{i}, \\
\left(\text { value }_{i} \mid \text { homeowner, married }\right)^{\text {home }}=\alpha+x_{i}^{\prime} \theta+e_{i},
\end{gathered}
$$

where value is the market value of investments in owner-occupied single-family homes, $z$ is a vector of household and household head characteristics including $\hat{y}_{h}(1-\hat{\alpha}) C \hat{o} v\left(\tilde{p}_{1}, \tilde{\pi}\right)$, and $x$ is a vector of household and individual characteristics including $\hat{y}_{k}\left(1-\hat{\alpha}_{k}\right) C \hat{o} v\left(p_{k}, \pi\right)$ of each spouse $k$ (see Section 5.1 for details).

Summary statistics and definitions of explanatory variables are reported in Tables 2 and 3, and in Appendix A.2. In accordance with Hypothesis 2, positive coefficients are expected on $\hat{y}(1-\hat{\alpha}) \operatorname{Cov}(\tilde{p}, \tilde{\pi})$. As a base case, $\hat{\alpha}$ is set to zero for all individuals. 
The empirical results of regression (10) are reported in Table 10, specifications (3) and (4). As expected, the value of the average investment in single-family homes increases with household size and age (estimates not reported). More importantly, the coefficient on $\hat{y}_{h} C \hat{o} v\left(\tilde{p}_{1}, \tilde{\pi}\right)$ is found to be positive and significant with a point estimate of 298 in specification (3). In specification (4), which includes income interaction effects, the point estimate is slightly higher at 331. In other words, a household whose unemployment risk tends to increase at the same time as local home prices tend to go down is shown to invest less on average in single-family homes, ceteris paribus.

To summarize, a one standard deviation increase in $\hat{y}_{h} C \hat{o} v\left(\tilde{p}_{1}, \tilde{\pi}\right)$ implies an increase in average investment in single-family homes of approximately SEK 96,000 (USD 13,300). ${ }^{33}$ Since the average home value in the sample is SEK 867,851 (median SEK 645,280), I conclude that the impact of $\hat{y}_{h} C \hat{o} v\left(\tilde{p}_{1}, \tilde{\pi}\right)$ on households' investments in owner-occupied housing is economically significant.

As a robustness check, a Tobit specification of the model is used as it takes into account the non-trivial proportion of the sample owning zero housing and hence may be more accurate than the ordinary OLS regression (10). In the Tobit specification the coefficient on $\hat{y}_{h} C \hat{o} v\left(\tilde{p}_{1}, \tilde{\pi}\right)$ is positive and statistically significant, with a marginal effect of 373 (see Table 10, specification (7)). This means that the results of the Tobit model are very similar to the OLS regression (10) results reported in Table 10, specification (4), although OLS and Tobit estimates are not directly comparable.

Further, the empirical results of regression (11), restricted to homeowners only, are reported in Table 10, specifications (5) and (6). The coefficient on $\hat{y}_{h} C \hat{o} v\left(\tilde{p}_{1}, \tilde{\pi}\right)$ is found to be strongly significant in this regression, with point estimates of 146 in specification (5) and 184 in specification (6), which includes income interaction effects. In other words, the coefficients

\footnotetext{
${ }^{33}$ The standard deviation of $\hat{y}_{h} \operatorname{Cov} v\left(\tilde{p}_{1}, \tilde{\pi}\right)$ is 322 (see Table 2) and the point estimate of the coefficient on $\hat{y}_{h} C \hat{o} v\left(\tilde{p}_{1}, \tilde{\pi}\right)$ is 298 in specification (3).
} 
on $\hat{y}_{h} C \hat{o} v\left(\tilde{p}_{1}, \tilde{\pi}\right)$ are reduced by roughly half compared to the case in which all households, i.e., both renters and homeowners, are included as in regression (10).

For homeowners, the value of the preferred investment in owner-occupied housing is observed; for current renters, however, we do not observe anything. As homeownership may be systematically correlated with unobservable characteristics, using only homeowners as in regression (11) may produce biased estimators due to sample selection. A Heckman two-step selection model is therefore used as a robustness check.

In the first step, homeownership probabilities are estimated for each household using probit regression (7), specification (2). In the second step, the inverse Mills ratio, $\lambda$, is estimated and included as an additional explanatory variable in OLS regression (11). Without the inverse Mills ratio, the point estimate of the coefficient on $\hat{y}_{h} C \hat{o} v\left(\tilde{p}_{1}, \tilde{\pi}\right)$ is 146 , as reported in Table 10, specification (5). As the point estimate of the coefficient on $\hat{y}_{h} C \hat{o} v\left(\tilde{p}_{1}, \tilde{\pi}\right)$ changes only slightly to 145 when the inverse Mills ratio is included as an additional explanatory variable (see Table 10, specification (8)), sample selection does not seem to significantly affect the results in this case.

Finally, the empirical results of regression (12) using the sample of married couples are reported in Table 11, specification (4). The point estimate of the coefficient on $\hat{y}_{1} C \hat{o} v\left(\tilde{p}_{1}, \tilde{\pi}\right)$ for the spouse with the highest reported disposable income, spouse 1, is strongly positive and significant and the estimate of 254 is higher then when using the whole sample (see above). For the lower-income spouse, spouse 2, however, the point estimate of the coefficient on $\hat{y}_{2} C \hat{o} v\left(\tilde{p}_{2}, \tilde{\pi}\right)$ is found to be small and insignificant. As reported in Section 5.1, $\hat{y}_{2} C \hat{o} v\left(\tilde{p}_{2}, \tilde{\pi}\right)$ might be measured with errors, since $\hat{y}_{2}$ is more likely to be affected by temporary negative income shocks than $\hat{y}_{1}$. Hence, attenuation bias could explain the lack of empirical significance of $\hat{y}_{2} C \hat{o} v\left(\tilde{p}_{2}, \tilde{\pi}\right)$. 


\subsection{Married Couples}

The objective of this section is to study whether married couples with different magnitudes of correlations between $\operatorname{Cov}\left(\tilde{p}_{1}, \tilde{\pi}\right)$ and $\operatorname{Cov}\left(\tilde{p}_{2}, \tilde{\pi}\right)$ differ in their housing investment decisions. Since $C \hat{o} v\left(\tilde{p}_{1}, \tilde{\pi}\right)$ and $C \hat{o} v\left(\tilde{p}_{2}, \tilde{\pi}\right)$ are found to be highly correlated when the spouses work in the same industry (see Table 8), same- and different-industry couples are used as proxies for high- and low-correlation couples in the empirical analysis (there is no information about occupation in the data), as specified in Hypotheses 3 and 4:

H3: $(i)$ The probability that a married couple has a value of $\operatorname{Cov}(\tilde{p}, \tilde{\pi})^{h}$ below the threshold level of $\overline{\operatorname{Cov}(\tilde{p}, \tilde{\pi})^{h}}$ and hence rents its home is larger if the spouses work in the same industry than if they work in different industries, ceteris paribus. (ii) The difference in rent probabilities between same- and different-industry couples increases with the mean and decreases with the variance of $\operatorname{Cov}(\tilde{p}, \tilde{\pi})^{h}$ values in the population, ceteris paribus.

H4: $(i)$ Conditional on ownership, a married couple has on average a higher value of $\operatorname{Cov}(\tilde{p}, \tilde{\pi})^{h}$ and thereby invests more in owner-occupied housing if the spouses work in the same industry than if they work in different industries, ceteris paribus. (ii) The differences in $\operatorname{Cov}(\tilde{p}, \tilde{\pi})^{h}$ and in housing investment, conditional on ownership, between same- and different-industry couples decreases with the mean and increases with the variance of $\operatorname{Cov}(\tilde{p}, \tilde{\pi})^{h}$ values in the population, ceteris paribus.

The results of the initial empirical tests of Hypotheses 3 and 4 are presented in Table 13. It shows the share of households that are renters and the average value of $C \hat{o} v(\tilde{p}, \tilde{\pi})^{h}$ conditional on ownership among same- and different-industry couples.

Table 13 
In line with the predictions of Hypothesis 3, same-industry couples are found to rent more often than different-industry couples; the share of households that are renters is 16 percent among same-industry couples and 14 percent among different-industry couples. Further, the difference in homeownership rates between same- and different industry couples is expected to increase with the mean and decrease with the variance of $\operatorname{Cov}(\tilde{p}, \tilde{\pi})^{h}$ values in the population (see Hypothesis 3). The sector with the highest average value and the lowest variance of $C \hat{o} v(\tilde{p}, \tilde{\pi})^{h}$ is the central government sector (see Table 6). In fact, the largest difference in homeownership rates between same- and different-industry couples ( 5.5 percentage points) is found for couples in which both spouses work in the central government sector. All differences between same- and different-industry couples are statistically significant.

On the other hand, in line with the predictions of Hypothesis 4, the average value of $C \hat{o} v(\tilde{p}, \tilde{\pi})^{h}$ conditional on ownership is -250 among same-industry couples and somewhat lower, -268, among different-industry couples. The difference in $\operatorname{Cov}(\tilde{p}, \tilde{\pi})^{h}$ between sameand different-industry couples is expected to decrease with the mean and increase with the variance of $\operatorname{Cov}(\tilde{p}, \tilde{\pi})^{h}$ values in the population (see Hypothesis 4). Since the private sector is the sector with the lowest average value and the highest variance of $C \hat{o} v(\tilde{p}, \tilde{\pi})^{h}$, the largest difference in average values of $\operatorname{Cov}(\tilde{p}, \tilde{\pi})^{h}$ conditional on ownership between sameand different-industry couples is expected in the private sector (see Table 6). This is in fact verified by the data; the average value of $C \hat{o} v(\tilde{p}, \tilde{\pi})^{h}$ conditional on ownership is -299 for same-industry couples and -353 for different-industry couples in the private sector. The difference of 54 is statistically significant.

Among the highest income earners the homeownership rate reaches almost 100 percent and the threshold value, $\overline{\operatorname{Cov}(\tilde{p}, \tilde{\pi})^{h}}$ is very low, which makes the comparison between sameand different industry couples less relevant. When households in the top quartile of the household income distribution are dropped, the difference in $C \hat{o} v(\tilde{p}, \tilde{\pi})^{h}$ between same- and different-industry couples in the private sector increases from 54 to 75 and the difference in 
homeownership rates between same- and different-industry couples in the central government sector increases slightly to 6 percentage points, as we expect (see Table 13, Panel B).

An interesting question is whether there are heterogeneous effects of working in the same industry within the private sector similarly to the differences between the government and private sectors described above. According to Hypothesis 4, a larger difference in $\operatorname{Cov}(\tilde{p}, \tilde{\pi})^{h}$ between same- and different-industry couples in the private sector, conditional on ownership, is expected if both spouses work in industries with a low expected value of $\operatorname{Cov}(\tilde{p}, \tilde{\pi})^{h}$ and a high variance of $\operatorname{Cov}(\tilde{p}, \tilde{\pi})^{h}$ than if they both work in industries with a high expected value of $\operatorname{Cov}(\tilde{p}, \tilde{\pi})^{h}$ and a low variance of $\operatorname{Cov}(\tilde{p}, \tilde{\pi})^{h}$, ceteris paribus. A specific industry $m$ is referred to as a low-mean-and-high-variance industry if the average value of $C \hat{o} v_{m}(\tilde{p}, \tilde{\pi})$ is below the average value of $C \hat{o} v(\tilde{p}, \tilde{\pi})$ for all industries and $\operatorname{Var}\left(C \hat{o} v_{m}(\tilde{p}, \tilde{\pi})\right)$ is larger than the variance of $C \hat{o} v(\tilde{p}, \tilde{\pi})$ for all industries. ${ }^{34}$

In fact, the average value of $C \hat{o} v(\tilde{p}, \tilde{\pi})^{h}$ conditional on ownership is -439 among couples in which the spouses work in the private sector and in the same low-mean-and-high-variance industry and -529 among couples in which the spouses work in the private sector and in a low-mean-and-high-variance industry but not in the same one (see Table 13, Panel B). For couples in which the spouses work in the private sector but not in any of the low-meanand-high-variance industries, the corresponding average values of $C \hat{o} v(\tilde{p}, \tilde{\pi})^{h}$ for same- and different-industry couples are -196 and -237 . In other words, the difference in $C \hat{o} v(\tilde{p}, \tilde{\pi})^{h}$ between same- and different-industry couples in the private sector is, as expected, larger within the group of industries with a low mean and a high variance of $C \hat{o} v(\tilde{p}, \tilde{\pi})$ than within the group of industries with a high mean and low variance of $C \hat{o} v(\tilde{p}, \tilde{\pi})$ (90 versus 41). The difference is statistically significant.

\footnotetext{
${ }^{34}$ The following industries fulfill these two conditions (see Table 6): construction, hotels and restaurants, real estate, renting and business activities and community, social and personal service activities.
} 
From the theoretical framework, it follows that same-industry couples on average have a higher value of $\operatorname{Cov}(\tilde{p}, \tilde{\pi})^{h}$, conditional on ownership, than different-industry couples. This is verified in the empirical analysis above. Hence, the next step is to find out whether the higher average value of $\operatorname{Cov}(\tilde{p}, \tilde{\pi})^{h}$ induces same-industry couples to invest more in owner-occupied housing on average, conditional on ownership. From the analysis above, we also know that same-industry couples tend to rent more often than different-industry couples. However, in the above analysis, I just compare simple means in homeownership rates between the two groups.

Next, I include same-industry indicator variables in formal regression models on tenure choice and on conditional housing demand in order to control for individual characteristics, such as age and income. Using the sample of married couples, I run the following regressions:

$$
\begin{gathered}
\left(\text { homeowner }_{i} \mid \text { married }\right)=\alpha+x_{i}^{\prime} \theta+I_{i}^{\prime} \xi+e_{i}, \\
\left(\text { value }_{i} \mid \text { homeowner, married }\right)=\alpha+x_{i}^{\prime} \theta+I_{i}^{\prime} \xi+e_{i},
\end{gathered}
$$

where homeowner indicates ownership of a single-family home, value is the market value of investments in owner-occupied single-family homes, $x$ is a vector of both household characteristics, such as household size and municipality of residence, and of individual characteristics of each spouse $k$, such as industry, sector, income, age group, unemployment risk, and $\hat{y}_{k}(1-\hat{\alpha}) \operatorname{Cov}\left(\tilde{p}_{k}, \tilde{\pi}\right) . I$ is a vector of indicator variables, indicating e.g. whether both spouses work in the same industry. Summary statistics and definitions of the included variables are provided in Tables 2 and 3, and in Appendix A.2. As above, $\hat{\alpha}$ is set to zero for all individuals.

The empirical results of probit regression (13) on homeownership and of OLS regression (14) on the value of the investment in owner-occupied housing are reported in Tables 11 
and 14. In all specifications, $\hat{y}_{1} C \hat{o} v\left(\tilde{p}_{1}, \tilde{\pi}\right)$ is significant and in line with the point estimates from the tenure choice regression above (see equation (8) in section 5.1) and the conditional demand regression (see equation (12) in section 5.2). The point estimates of the coefficient on $\hat{y}_{2} C \hat{o} v\left(\tilde{p}_{2}, \tilde{\pi}\right)$ are, once again, found to be small and insignificant in both the tenure choice and in the conditional demand regressions.

\section{Table 14}

In specifications (2) and (5) in Table 11, a same-industry indicator variable is included. In line with the predictions of Hypothesis 3, a negative, albeit small, significant effect on homeownership is found. ${ }^{35}$ The expected probability of homeownership is 1 percentage point lower for a same-industry couple than it is for a different-industry couple, ceteris paribus (see Table 11, specification (2)). On the other hand, in line with the predictions of Hypothesis 4, same-industry couples invest SEK 66,727 more on average in single-family homes, conditional on ownership, than different-industry couples, ceteris paribus (see Table 11, specification (5)). This effect is economically significant (the average home value is SEK 1,468,622 in the sample of home-owning married couples) and is consistent with the results presented in Table 13 which shows that the average value of $C \hat{o} v(\tilde{p}, \tilde{\pi})^{h}$ conditional on ownership is higher among same-industry couples than it is among different-industry couples.

The highest correlations between $C \hat{o} v\left(\tilde{p}_{1}, \tilde{\pi}\right)$ and $C \hat{o} v\left(\tilde{p}_{2}, \tilde{\pi}\right)$ are found for couples in which the husband and wife work in the same industry and in the same sector (see Table

\footnotetext{
${ }^{35}$ If we do not control for the household-specific covariance between individual unemployment risks and local home prices, $\operatorname{Cov}(\tilde{p}, \tilde{\pi})^{h}$, in the regression analysis, a negative (positive) relationship between the indicator variable indicating whether both spouses work in the same industry and homeownership (conditional investments in owner-occupied housing) is predicted by theory (see Hypotheses 3 and 4). If we control for $\operatorname{Cov}(\tilde{p}, \tilde{\pi})^{h}$, however, we expect to find no relationship in theory between the same-industry indicator variable and homeownership or conditional investments in housing. In this case, we cannot control for $\operatorname{Cov}(\tilde{p}, \tilde{\pi})^{h}$ at the household level in a precise way. In case of measurement errors in the income of the lower-income spouse (i.e., spouse 2) there is, as discussed in Section 5.1, attenuation bias. As a consequence, the point estimates of the coefficient on $\hat{y}_{2} C \hat{o} v\left(\tilde{p}_{2}, \tilde{\pi}\right)$ are found to be small and insignificant in both the tenure choice and in the conditional demand regressions. As a robustness check, I run regressions (13) and (14) excluding $\hat{y}_{1} \operatorname{Co} v\left(\tilde{p}_{1}, \tilde{\pi}\right)$ and/or $\hat{y}_{2} \operatorname{Co} v\left(\tilde{p}_{2}, \tilde{\pi}\right)$, and the results are very similar.
} 
8). An indicator variable indicating whether the spouses work in the same industry and in the same sector is therefore added in specifications (3) and (6) in Table 11. The effect of working in the same industry and sector might however differ across sectors, since we expect the largest difference in homeownership rates between same- and different-industry couples in the central government sector (see Hypothesis 3) and the largest difference in conditional housing demand between same- and different-industry couples in the private sector (see Hypothesis 4). In order to test this, interaction variables between same industry and sector and the private, the local government, and the central government sectors are added in specifications (1) and (2) in Table 14.

In fact, couples in which the spouses work in the same industry and in the same sector invest an additional SEK 109,701 on average in single-family homes, conditional on ownership, ceteris paribus (see Table 11, specification (6)). ${ }^{36}$ The largest difference is found, in line with expectations, in the private sector in which same-industry couples on average invest SEK 127,852 more in single-family homes conditional on ownership than different-industry couples, ceteris paribus (see Table 14, specification (2)). In the local (central) government sector, same-industry couples invest SEK 41,906 (SEK 25,780) more on average.

These results are consistent with the results reported in Table 13. To summarize, the difference in $\operatorname{Cov}(\tilde{p}, \tilde{\pi})^{h}$ between same- and different-industry couples is expected to decrease with the mean and increase with the variance of $\operatorname{Cov}(\tilde{p}, \tilde{\pi})^{h}$ values in the population (see Hypothesis 4). Since the private sector is the sector with the lowest average value and the highest variance of $C \hat{o} v(\tilde{p}, \tilde{\pi})^{h}$ (see Table 6), the largest differences in average values of $\operatorname{Cov}(\tilde{p}, \tilde{\pi})^{h}$ and average investments in owner-occupied housing between same- and differentindustry couples, conditional on ownership, are expected in the private sector. This is in fact verified by the data; the average value of $C \hat{o} v(\tilde{p}, \tilde{\pi})^{h}$ conditional on ownership is -299

\footnotetext{
${ }^{36}$ Since the indicator variable for same industry is found to be insignificant in this specification, same industry and sector seems to be the most relevant measure of a high correlation between spouses' unemployment risks.
} 
for same-industry couples and -353 for different-industry couples in the private sector (see Table 13), and same-industry couples invest on average SEK 127,852 more in single-family homes conditional on ownership than different-industry couples in the private sector, ceteris paribus (see Table 14, specification (2)). In the government sectors, these differences are much smaller in magnitude.

In the tenure choice regression, the same-industry and same-sector indicator variables are insignificant (see Table 11, specification (3)). In line with expectations, however, I find that the probability of homeownership is 4 percentage points lower for same-industry couples compared to different-industry couples when both spouses work in the central government sector, ceteris paribus (see Table 14, specification (1)). No significant negative effects on homeownership rates are found for same-industry couples compared to different-industry couples in the local government and private sectors.

These results are very similar to the results presented in Table 13, where I do not control for household characteristics. To summarize, the difference in homeownership rates between same- and different industry couples is expected to increase with the mean and decrease with the variance of $\operatorname{Cov}(\tilde{p}, \tilde{\pi})^{h}$ values in the population (see Hypothesis 3). The sector with the highest average value and the lowest variance of $C \hat{o} v(\tilde{p}, \tilde{\pi})^{h}$ values is the central government sector (see Table 6). In fact, in both Table 13 and 14, the largest difference in homeownership rates between same- and different-industry couples is found for couples in which both spouses work in the central government sector.

\subsection{Investment Horizon, Investor Sophistication and Other Im- portant Issues}

In this section, a couple of important issues, such as expected investment horizon and investor financial sophistication, that might have important implications for the empirical results 
outlined above are further investigated. In this analysis we have to keep in mind, though, that many of the variables, for instance income and education level, are highly correlated.

\subsubsection{Expected Investment Horizon}

Since house price risk decreases as the expected investment horizon increases, the effect of $\hat{y} C \hat{o} v(\tilde{p}, \tilde{\pi})$ on households' housing investment decisions is expected to be smaller in magnitude for households with long expected tenures. To test this hypothesis empirically, data from LINDA is used to estimate moving probabilities and expected investment horizons for each sampled household.

In the first step, household-specific moving probabilities are estimated annually from 1985 to 2001 using a probit regression model in a manner similar to how unemployment probabilities are estimated (see Section 4.3.1 for details). ${ }^{37}$ The household-specific expected investment horizon is simply estimated as one over the average of the annual household specific moving probabilities. In the next step, OLS regression (10) on the value of households' investments in single-family homes is run with the household-specific expected investment horizon variable interacted with all other explanatory variables in the model. Following from the above reasoning, a negative coefficient is expected on the interaction variable between $\hat{y}_{h} C \hat{o} v\left(\tilde{p}_{1}, \tilde{\pi}\right)$ and the expected investment horizon.

The empirical results, presented in Table 15, specification (1), support this hypothesis. The point estimate of the coefficient on the interaction variable between $\hat{y}_{h} C \hat{o} v\left(\tilde{p}_{1}, \tilde{\pi}\right)$ and the expected investment horizon is negative and statistically significant. In fact, for an expected investment horizon of 36 years (i.e., the $99^{\text {th }}$ percentile), the estimated average effect of $\hat{y}_{h} C \hat{o} v\left(\tilde{p}_{1}, \tilde{\pi}\right)$ on the value of household investments in single-family homes is close to zero. To summarize, my empirical findings indicate, in line with previous literature, that

\footnotetext{
${ }^{37}$ There is no data on moves for 2002 and 2003 in the LINDA data set. Explanatory variables are age group, country of birth, education, family size, gender and marital status of the individual with the highest reported disposable income in the household.
} 
the expected investment horizon is a key variable when it comes to households' housing investment decisions.

Table 15

\subsubsection{Recent Move}

We also expect households that recently moved to a new home to have incorporated more current information about their individual unemployment risks and local home price dynamics into their housing investment decisions compared to households that moved to their current home many years ago. A recent move may also be an indication of a more mobile household and hence of a shorter expected investment horizon. In other words, the coefficient on $\hat{y} C \hat{o} v(\tilde{p}, \tilde{\pi})$ is expected to be larger in magnitude for households that moved, say, during the last five years.

To test this hypothesis empirically, OLS regression (10) on the value of households' investments in single-family homes is run with a dummy variable, which indicates whether a household moved during the last five years, interacted with all other explanatory variables in the model. Following the reasoning above, a positive coefficient is expected on the interaction variable between $\hat{y}_{h} C \hat{o} v\left(\tilde{p}_{1}, \tilde{\pi}\right)$ and the dummy variable indicating a recent move.

The empirical results, presented in Table 15, specification (2), support this hypothesis. The point estimate of the coefficient on $\hat{y}_{h} C \hat{o} v\left(\tilde{p}_{1}, \tilde{\pi}\right)$ for households that moved during the last five years is 477 compared to 303 for households that have lived in their current home for more than five years, ceteris paribus. This difference of 174 in point estimates is statistically significant.

Similar results are found for home-owning married couples. When OLS regression (12) on married couples' investments in single-family homes is run with a dummy variable, which indicates whether a married couple moved during the last five years, interacted with all other 
explanatory variables in the model, the point estimate of the coefficient on $\hat{y}_{1} C \hat{o} v\left(\tilde{p}_{1}, \tilde{\pi}\right)$ of the spouse with highest reported disposable income is 662 for couples who changed residence during the last five years and only 199 for couples who have lived in their current home for more than five years (see Table 15, specification (8)). This difference of 463 in point estimates is statistically significant.

\subsubsection{Borrowing Constraints}

There is a possibility that banks and other credit institutions impose borrowing constraints on households with large negative covariance values between individual unemployment risks and local home prices. To find out if this is the case, OLS regression (11) on the value of homeowners' investments in single-family homes is run with a dummy variable, which indicates whether a household is below the $10^{\text {th }}$ debt percentile (i.e., households with total debt not exceeding SEK 144,000), interacted with all other explanatory variables in the model.

The empirical results, presented in Table 15, specification (3), show that the point estimate of the coefficient on $\hat{y}_{h} C \hat{o} v\left(\tilde{p}_{1}, \tilde{\pi}\right)$ is 156 for homeowners with large amounts of debt and 206 for homeowners with no or little debt. The difference in point estimates is rather small and is not statistically significant. In other words, the empirical results seem to be driven mainly by individual household decisions and not by lender policies. Nonetheless, this is an important issue that should be investigated more thoroughly in future work.

\subsubsection{Rent Regulation}

Another important issue that might have an impact on the empirical results is the rent regulation (described in Section 4.2.1), which is primarily binding in the central part of Stockholm. In order to evaluate if the empirical results are affected by this regulation, probit regression (7) on households' tenure choice and OLS regression (11) on the value 
of homeowners' investments in single-family homes are run with a dummy variable, which indicates whether a household lives in the Stockholm metropolitan area, interacted with all other explanatory variables in the model.

The empirical results, presented in Table 15, specifications (4) and (7), indicate that $\hat{y}_{h} C \hat{o} v\left(\tilde{p}_{1}, \tilde{\pi}\right)$, on the one hand, has a smaller effect on tenure choice for households in the Stockholm metropolitan area. When it comes to conditional housing demand, on the other hand, the estimated coefficient on $\hat{y}_{h} C \hat{o} v\left(\tilde{p}_{1}, \tilde{\pi}\right)$ is much larger in Stockholm than in the rest of the country: 319 versus 115 . The difference in point estimates, though, is not statistically significant.

A conclusion one may draw from these empirical results is that some households in the Stockholm metropolitan area that would be better off renting are forced instead to buy their homes due to the rent regulation and the lack of suitable homes available for immediate rent. When these households buy a home, however, they compensate for this fact, at least partially, by buying a less expensive home.

\subsubsection{Unemployment Benefits}

Another important issue is the financial loss in case of unemployment. One measure of this loss is the individual estimate of $\hat{\alpha}$, which differs across individuals as a consequence of the

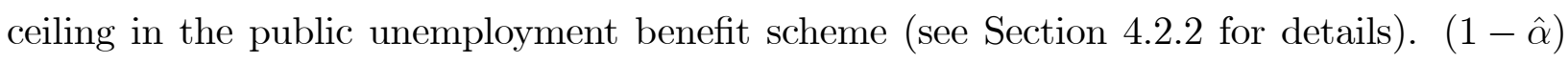
increases with income and a high value of $(1-\hat{\alpha})$ implies a relatively larger financial loss in case of unemployment.

To test the hypothesis that households that lose more financially in the event of unemployment put more weight on $\hat{y}_{h} C \hat{o} v\left(\tilde{p}_{1}, \tilde{\pi}\right)$ in their housing investment decisions, ceteris paribus, OLS regression (10) on the value of households' investments in single-family homes is run with additional interaction variables between $(1-\hat{\alpha})$ and all other explanatory variables in the model. A positive coefficient is expected on the interaction variable between $(1-\hat{\alpha})$ 
and $\hat{y}_{h} C \hat{o} v\left(\tilde{p}_{1}, \tilde{\pi}\right)$. Since it is not straightforward to estimate $(1-\hat{\alpha})$ at the household level for dual-income households, only single households are included in this case. Further, since $\hat{y}_{h} C \hat{o} v\left(\tilde{p}_{1}, \tilde{\pi}\right)$ is shown to be less relevant in the housing investment decision for households with very long investment horizons, households above the $90^{t h}$ expected investment horizon percentile (corresponding to 13.9 years), using the method described in Section 5.4.1, are also excluded from the sample. All remaining individuals are assumed to be members of an unemployment insurance fund and holdings of private unemployment insurances are disregarded.

The empirical results, reported in Table 15, specification (5), indicate, in line with the hypothesis above, that the point estimate of the coefficient on $\hat{y}_{h} C \hat{o} v\left(\tilde{p}_{1}, \tilde{\pi}\right)$ increases with $(1-\hat{\alpha})$ since the interaction term between $\hat{y}_{h} C \hat{o} v\left(\tilde{p}_{1}, \tilde{\pi}\right)$ and $(1-\hat{\alpha})$ is positive and statistically significant. For the group of individuals for whom $(1-\hat{\alpha})$ equals 0.20 , i.e., individuals with a monthly salary not exceeding SEK 20,075, the total estimated effect of $\hat{y}_{h} C \hat{o} v\left(\tilde{p}_{1}, \tilde{\pi}\right)$ on the investment in single-family homes is close to zero. Since $(1-\hat{\alpha})$ increases with income, however, an alternative interpretation is that high-income individuals are more aware of the unemployment-home price covariance risk (see more in the next section on investor sophistication).

\subsubsection{Investor Sophistication}

The final issue concerns investor sophistication. All of the regressions control for education and income. However, the impact of a given $\hat{y} C \hat{o} v(\tilde{p}, \tilde{\pi})$ on the housing investment decision might depend on an individual's financial sophistication level, ceteris paribus. The hypothesis is that highly educated households are more aware of the unemployment-home price covariance risk than less educated households.

To test this hypothesis empirically, OLS regression (10) on the value of households' investments in single-family homes is run with a dummy variable, which indicates whether 
an individual belong to the highly-educated group (i.e., at least 2 years of college), interacted with all other explanatory variables in the model. In order to avoid households in which one member is highly educated and the other/s not, only single households are included in the sample. Since we also know that the financial loss in case of unemployment, $(1-\hat{\alpha})$, and education levels increase with income, only individuals above the $75^{\text {th }}$ income percentile are included. A positive coefficient is expected on the interaction variable between $\hat{y}_{h} C \hat{o} v\left(\tilde{p}_{1}, \tilde{\pi}\right)$ and the high-education indicator variable.

The empirical results, presented in Table 15, specification (6), support this hypothesis. The point estimate of the coefficient on $\hat{y}_{h} C \hat{o} v\left(\tilde{p}_{1}, \tilde{\pi}\right)$ is 513 and significant for the group of highly-educated individuals and much smaller in magnitude, 184, for the group of lesseducated individuals. In other words, there are indications that the empirical results are primarily driven by highly-educated high-income individuals. We have to keep in mind, though, that expected investment horizon, unemployment duration etc. might depend on education level.

\section{Conclusions}

In a basic theoretical model that incorporates the fact that unemployment is the most important component of labor income risk, I show that the optimal level of investment in owner-occupied housing increases with the covariance between individual unemployment risks and returns to owner-occupied housing. ${ }^{38}$ The underlying idea is that if there is a negative covariance between returns to owner-occupied housing and the risk of becoming unemployed, the housing asset becomes riskier for households to hold. I also show, in a novel way, that married couples in which both spouses work in the same industry, on the one hand, invest more on average in single-family homes, conditional on ownership, than

\footnotetext{
${ }^{38}$ Note that a positive covariance between unemployment risks and returns to owner-occupied housing implies a negative covariance between labor income and returns to owner-occupied housing, ceteris paribus.
} 
couples in which spouses work in different industries, ceteris paribus. On the other hand, the probability of homeownership is somewhat lower for same-industry couples.

These hypotheses are supported by the data. Using a unique, register-based Swedish micro database on employment and real estate holdings, I find that a one standard deviation increase in the unemployment risk-home price covariance implies an increase in the average investment in single-family homes of approximately SEK 96,000 (USD 13,300). Further, I find that the expected probability of homeownership is 1 percentage point lower for a sameindustry couple than it is for a different-industry couple, ceteris paribus. Same-industry couples, on the other hand, invest SEK 66,727 (USD 9,200) more on average in single-family homes, conditional on ownership, than different-industry couples, ceteris paribus.

The empirical effects turn out to be greatest among highly educated households, households with short expected investments horizons and, consistent with the conditions of the Swedish public unemployment benefit schemes, high-income households.

One possibility, though, which I discuss in the paper, is that banks and other credit institutions may impose borrowing constraints on households with large negative covariance values between individual unemployment risks and local home prices. In the data, however, I find similar results for homeowners with very low absolute levels of debt, i.e., households less likely to face credit constraints. Nonetheless, this is an important issue that should be investigated more thoroughly in future work. Another issue that is discussed in the paper is the consequences of the rental control policy in Sweden. A conclusion that may be drawn from my empirical results is that some households that would be better off renting due to the unemployment risk-home price covariance risk are forced instead to buy their homes because of the rent regulation and the lack of suitable homes available for immediate rent.

It is hoped that this paper will provide useful insights into the large cross-sectional variation in household portfolios of risky assets and that the knowledge about household financial behavior gained in this study can be used in further research, for example in measuring the 
efficiency of household asset portfolios or estimating the possible gains accruing from the development of various real estate derivatives. A possible future extension of this paper would be to include risky financial assets, such as stocks and bonds, into the model. 


\section{A Appendix}

\section{A.1 Proof of Proposition 2}

Proposition 1 states that if the value of $\operatorname{Cov}(\tilde{p}, \tilde{\pi})^{h}$ falls below a certain threshold level, $\overline{\operatorname{Cov}(\tilde{p}, \tilde{\pi})^{h}}$, renting is preferable to owning. If the distribution of $\operatorname{Cov}(\tilde{p}, \tilde{\pi})^{h}$ in the population is assumed to be normal, the well-known properties of a truncated normal distribution can be used. The probability that a married couple in the population rents its home is then

$$
\operatorname{Pr}(\text { renter }) \equiv \operatorname{Pr}\left(\operatorname{Cov}(\tilde{p}, \tilde{\pi})^{h}<\overline{\operatorname{Cov}(\tilde{p}, \tilde{\pi})^{h}}\right)=\Phi(c),
$$

and the expected value of $\operatorname{Cov}(\tilde{p}, \tilde{\pi})^{h}$, conditional on ownership, is

$$
\begin{aligned}
E\left(\operatorname{Cov}(\tilde{p}, \tilde{\pi})^{h} \mid \text { owner }\right) & \equiv E\left(\operatorname{Cov}(\tilde{p}, \tilde{\pi})^{h} \mid \operatorname{Cov}(\tilde{p}, \tilde{\pi})^{h}>\overline{\operatorname{Cov}(\tilde{p}, \tilde{\pi})^{h}}\right) \\
& =E\left(\operatorname{Cov}(\tilde{p}, \tilde{\pi})^{h}\right)+\operatorname{Std} \operatorname{Dev}\left(\operatorname{Cov}(\tilde{p}, \tilde{\pi})^{h}\right) Z(c)
\end{aligned}
$$

where $\Phi$ is the CDF of a standard normal distribution, $c=\left(\frac{\overline{\operatorname{Cov}(\tilde{p}, \tilde{\pi})^{h}}-E\left(\operatorname{Cov}(\tilde{p}, \tilde{\pi})^{h}\right)}{\operatorname{StdDev}\left(\operatorname{Cov}(\tilde{p}, \tilde{\pi})^{h}\right)}\right)$ and $Z(c)=(\phi(c) / \Phi(c))$.

If the truncation point is below the mean, i.e., $\left.\overline{\operatorname{Cov}(\tilde{p}, \tilde{\pi})^{h}}\right)<E\left(\operatorname{Cov}(\tilde{p}, \tilde{\pi})^{h}\right)$, the derivative of Equation (15) w.r.t. the standard deviation of $\operatorname{Cov}(\tilde{p}, \tilde{\pi})^{h}$ is positive:

$$
\left(\frac{\partial \operatorname{Pr}(\text { renter })}{\partial \operatorname{StdDev}\left(\operatorname{Cov}(\tilde{p}, \tilde{\pi})^{h}\right)}\right)=-\frac{1}{\sigma} c \phi(c)>0 \text { if } c<0
$$

That is, the higher the standard deviation of $\operatorname{Cov}(\tilde{p}, \tilde{\pi})^{h}$ in a population, the higher the probability that a married couple in that population rents, given a certain truncation point of $\overline{\operatorname{Cov}(\tilde{p}, \tilde{\pi})^{h}}$.

Furthermore, the derivative of equation (16) w.r.t. the standard deviation of $\operatorname{Cov}(\tilde{p}, \tilde{\pi})^{h}$ 
is always positive (for proof, see e.g. Sampford, 1953):

$$
\left(\frac{\partial E\left(\operatorname{Cov}(\tilde{p}, \tilde{\pi})^{h} \mid \text { owner }\right)}{\partial \operatorname{Std} \operatorname{Dev}\left(\operatorname{Cov}(\tilde{p}, \tilde{\pi})^{h}\right)}\right)=Z(c)(1-c(Z(c)-c))>0 .
$$

That is, the higher the standard deviation of $\operatorname{Cov}(\tilde{p}, \tilde{\pi})^{h}$ in a population, the higher the expected value of $\operatorname{Cov}(\tilde{p}, \tilde{\pi})^{h}$, conditional on ownership, given a certain truncation point of $\overline{\operatorname{Cov}(\tilde{p}, \tilde{\pi})^{h}}$.

The variance of $\operatorname{Cov}(\tilde{p}, \tilde{\pi})^{h}$ in the population of dual-earning married couples is:

$$
\operatorname{Var}\left(\operatorname{Cov}(\tilde{p}, \tilde{\pi})^{h}\right) \equiv \operatorname{Var}\left(\sum_{k=1}^{2}\left(1-\alpha_{k}\right) w_{k, 2} \operatorname{Cov}\left(\tilde{p}_{k, 2}, \tilde{\pi}_{2}\right)\right)
$$

That is, the variance of $\operatorname{Cov}(\tilde{p}, \tilde{\pi})^{h}$ increases with the correlation between $\operatorname{Cov}\left(\tilde{\pi}_{2}, \tilde{p}_{1,2}\right)$ and $\operatorname{Cov}\left(\tilde{\pi}_{2}, \tilde{p}_{2,2}\right)$, all else equal. Hence, the standard deviation of $\operatorname{Cov}(\tilde{p}, \tilde{\pi})^{h}$ is higher in the subpopulation of married couples with high correlation between $\operatorname{Cov}\left(\tilde{\pi}_{2}, \tilde{p}_{1,2}\right)$ and $\operatorname{Cov}\left(\tilde{\pi}_{2}, \tilde{p}_{2,2}\right)$ than it is in the subpopulation of married couples with low correlation between $\operatorname{Cov}\left(\tilde{\pi}_{2}, \tilde{p}_{1,2}\right)$ and $\operatorname{Cov}\left(\tilde{\pi}_{2}, \tilde{p}_{2,2}\right)$, all else equal:

$$
\left.\left.\operatorname{StdDev}\left(\operatorname{Cov}(\tilde{p}, \tilde{\pi})^{h}\right) \mid \text { high corr. }\right)>\operatorname{Std} \operatorname{Dev}\left(\operatorname{Cov}(\tilde{p}, \tilde{\pi})^{h}\right) \mid \text { low corr. }\right)
$$

From equations (17) and (20) it follows that the probability that a married couple in the subpopulation with high correlation between $\operatorname{Cov}\left(\tilde{\pi}_{2}, \tilde{p}_{1,2}\right)$ and $\operatorname{Cov}\left(\tilde{\pi}_{2}, \tilde{p}_{2,2}\right)$ rents its home is higher than the probability that a married couple in the subpopulation with low correlation between $\operatorname{Cov}\left(\tilde{\pi}_{2}, \tilde{p}_{1,2}\right)$ and $\operatorname{Cov}\left(\tilde{\pi}_{2}, \tilde{p}_{2,2}\right)$ rents its home, all else equal:

$$
\operatorname{Pr}(\text { renter } \mid \text { high corr. })>\operatorname{Pr}(\text { renter } \mid \text { low corr. }) \text {. }
$$

In a similar way, from equations (18) and (20) it follows that the expected value of 
$\operatorname{Cov}(\tilde{p}, \tilde{\pi})^{h}$, conditional on ownership, is higher for married couples with high correlation between $\operatorname{Cov}\left(\tilde{\pi}_{2}, \tilde{p}_{1,2}\right)$ and $\operatorname{Cov}\left(\tilde{\pi}_{2}, \tilde{p}_{2,2}\right)$ than for couples with low correlation between $\operatorname{Cov}\left(\tilde{\pi}_{2}, \tilde{p}_{1,2}\right)$ and $\operatorname{Cov}\left(\tilde{\pi}_{2}, \tilde{p}_{2,2}\right)$, all else equal:

$$
E\left(\operatorname{Cov}(\tilde{p}, \tilde{\pi})^{h} \mid \text { owner \& high corr. }\right)>E\left(\operatorname{Cov}(\tilde{p}, \tilde{\pi})^{h} \mid \text { owner \& low corr. }\right)
$$

Furthermore, under the additional assumption that $(-1<c<0)$ the derivative of equation (17) with respect to the expected value of $\operatorname{Cov}(\tilde{p}, \tilde{\pi})^{h}$ is positive:

$$
\left(\frac{\partial^{2} \operatorname{Pr}(\text { renter })}{\partial \operatorname{StdDev}\left(\operatorname{Cov}(\tilde{p}, \tilde{\pi})^{h}\right) \partial E\left(\operatorname{Cov}(\tilde{p}, \tilde{\pi})^{h}\right)}\right)=\left(\frac{1}{\sigma^{2}}\right) \phi(c)\left(1-c^{2}\right)>0 \text { if }(-1<c<1)
$$

and the derivative of equation (17) with respect to the standard deviation of $\operatorname{Cov}(\tilde{p}, \tilde{\pi})^{h}$ is negative:

$$
\left(\frac{\partial^{2} \operatorname{Pr}(\text { renter })}{\partial\left(\operatorname{StdDev}\left(\operatorname{Cov}(\tilde{p}, \tilde{\pi})^{h}\right)\right)^{2}}\right)=\left(\frac{1}{\sigma^{2}}\right) c \phi(c)\left(2-c^{2}\right)<0 \text { if }(-\sqrt{2}<c<0) .
$$

That is, the difference in homeownership rates between low- and high-correlation couples increases with $E\left(\operatorname{Cov}(\tilde{p}, \tilde{\pi})^{h}\right)$ and decreases with the standard deviation of $\operatorname{Cov}(\tilde{p}, \tilde{\pi})^{h}$ in the population.

Finally, the derivative of Equation (18) with respect to the expected value of $\operatorname{Cov}(\tilde{p}, \tilde{\pi})^{h}$ is negative:

$$
\left(\frac{\partial^{2} E\left(\operatorname{Cov}(\tilde{p}, \tilde{\pi})^{h} \mid \text { owner }\right)}{\partial \operatorname{StdDev}\left(\operatorname{Cov}(\tilde{p}, \tilde{\pi})^{h}\right) \partial E\left(\operatorname{Cov}(\tilde{p}, \tilde{\pi})^{h}\right)}\right)=\frac{1}{\sigma} c \lambda(c)<0 \text { if } c<0
$$

and the derivative of Equation (18) with respect to the standard deviation of $\operatorname{Cov}(\tilde{p}, \tilde{\pi})^{h}$ is 
positive (for proof, see e.g. Sampford, 1953):

$$
\left(\frac{\partial^{2} E\left(\operatorname{Cov}(\tilde{p}, \tilde{\pi})^{h} \mid \text { owner }\right)}{\partial\left(\operatorname{Std} \operatorname{Dev}\left(\operatorname{Cov}(\tilde{p}, \tilde{\pi})^{h}\right)\right)^{2}}\right)=\frac{1}{\sigma} c^{2} \lambda(c)>0,
$$

where $\lambda(c) \equiv(Z(c)((Z(c)-c)(2 Z(c)-c)-1))>0$. In other words, the difference in housing investments between low- and high-correlation couples, conditional on ownership, decreases with $E\left(\operatorname{Cov}(\tilde{p}, \tilde{\pi})^{h}\right)$ and increases with the standard deviation of $\operatorname{Cov}(\tilde{p}, \tilde{\pi})^{h}$ in the population. 


\section{A.2 Descriptions of Variables}

Age group: Dummies for (1) 26-30 year olds, (2) 31-35 year olds, (3) 36-40 year olds, (4), 41-45 year olds, (5) 46-50 year olds, (6) 51-55 year olds and (7) 56-60 year olds

Civil status change: Dummy for whether the individual has changed civil status since January 1, 1999

Country of birth: Dummies for (1) Sweden, (2) Nordic countries, (3) EU15 + 6 OECD countries and (4) all other countries

Education (field of study): (1) General education, (2) teaching methods and teacher education, (3) humanities and arts, (4) social sciences, law, commerce and administration, (5) natural sciences, mathematics and computing, (6) engineering and manufacturing, (7) agriculture, forestry and veterinary medicine, (8) health care, nursing and social care, and (9) services

Education (level): (1) Primary and lower secondary education less than nine years, (2) primary and lower secondary education nine (or 10) years, (3) upper secondary education, (4) post-secondary education less than two years, (5) post-secondary education two years or more and (6) postgraduate education

Industry: Dummies for (1) agriculture, hunting and forestry, (2) fishing, (3) mining and quarrying, (4) manufacturing, (5) electricity, gas and water supply, (6) construction, (7) wholesale and retail trade, repair of motor vehicles, motorcycles and personal and household goods, (8) hotels and restaurants, (9) transport, storage and communication, (10) financial intermediation, (11) real estate, renting and business activities, (12) public administration and defense, compulsory social security and extra-territorial organizations and bodies, (13) education, health and social work, and (14) other community, social and personal service activities 
Move: Dummy for whether the individual has changed place of residence since January 1, 1999

Region: Dummies for 70 A-regions (local labor markets)

Sector: Dummies for (1) central government sector, (2) local government (municipality) sector and (3) private sector 


\section{A.3 Tables}

Table A1: Conditions of public unemployment insurance programs in Sweden, Germany and the U.K.

\begin{tabular}{|c|c|c|c|c|c|c|}
\hline Country & Year & $\begin{array}{l}\text { Eligibility } \\
\text { conditions }\end{array}$ & $\begin{array}{l}\text { Waiting } \\
\text { period }\end{array}$ & $\begin{array}{c}\text { Maximum } \\
\text { Duration }\end{array}$ & $\begin{array}{c}\text { Initial payment } \\
\text { rate } \\
\text { (\% of earnings) }\end{array}$ & $\begin{array}{l}\text { Coverage } \\
\text { rate }\end{array}$ \\
\hline \multirow[t]{2}{*}{ Sweden } & 1995 & $\begin{array}{l}E: 6 \text { months in last } \\
\text { year } C: 12 \text { months }\end{array}$ & 5 days & 14 months & $\begin{array}{l}75 \% \text { of gross } \\
\text { earnings }\end{array}$ & $\mathrm{n} / \mathrm{a}$ \\
\hline & 2002 & $\begin{array}{l}E: 6 \text { months in last } \\
\text { year } C: 12 \text { months }\end{array}$ & 5 days & 14 months & $\begin{array}{l}80 \% \text { of gross } \\
\text { earnings }\end{array}$ & 0.85 \\
\hline \multirow[t]{2}{*}{ Germany } & 1995 & $\begin{array}{l}E: 12 \text { months } C: 12 \\
\text { months in } 3 \text { years }\end{array}$ & None & 12 months & $\begin{array}{l}60 \% \text { of net } \\
\text { earnings }\end{array}$ & 0.77 \\
\hline & 2002 & $\begin{array}{l}E: 12 \text { months } C: 12 \\
\text { months in } 3 \text { years }\end{array}$ & None & 12 months & $\begin{array}{l}60 \% \text { of net } \\
\text { earnings }\end{array}$ & 0.70 \\
\hline \multirow[t]{2}{*}{ U.K. } & 1995 & $C: 2$ years & 3 days & 6 months & $18 \%$ of APW & $\mathrm{n} / \mathrm{a}$ \\
\hline & 2002 & $C: 2$ years & 3 days & 6 months & $14 \%$ of APW & 0.82 \\
\hline
\end{tabular}

Note: $E$ represents the employment condition, $C$ the contribution condition, Coverage the percentage of unemployed individuals covered by unemployment insurance and $A P W$ the average production worker. Source: Duman (2005).

Table A2: Share of organizations offering employee stock ownership plans and profitsharing programs to different categories of personnel

\begin{tabular}{lcccccccc}
\hline \hline & \multicolumn{2}{c}{ Management } & \multicolumn{2}{c}{$\begin{array}{c}\text { Professional/ } \\
\text { Technical }\end{array}$} & \multicolumn{2}{c}{$\begin{array}{c}\text { Clerical/ } \\
\text { Administrative }\end{array}$} & \multicolumn{2}{c}{ Manual } \\
\hline & ESOP & Profits & ESOP & Profits & ESOP & Profits & ESOP & Profits \\
\hline Germany & $11.6 \%$ & $60.6 \%$ & $8.1 \%$ & $26.5 \%$ & $7.7 \%$ & $17.1 \%$ & $5.9 \%$ & $11.8 \%$ \\
France & $14.8 \%$ & $75.9 \%$ & $7.6 \%$ & $74.9 \%$ & $7.0 \%$ & $74.7 \%$ & $6.2 \%$ & $59.8 \%$ \\
Sweden & $7.1 \%$ & $15.3 \%$ & $3.8 \%$ & $12.5 \%$ & $4.1 \%$ & $14.2 \%$ & $3.3 \%$ & $11.7 \%$ \\
U.K. & $30.5 \%$ & $26.1 \%$ & $21.4 \%$ & $22.1 \%$ & $19.1 \%$ & $21.0 \%$ & $16.6 \%$ & $18.0 \%$ \\
\hline
\end{tabular}

Note: ESOP stands for employee stock ownership plan and Profits refers to a profit-sharing program. The data are from the 1995 wave of the Cranfield Network on European Human Resource Management dataset (Cranet-E). Source: Festing, Groening, Kabst, and Weber (1999). 


\section{References}

[1] Agell, J., and H. Bennmarker, "Endogenous Wage Rigidity," CESifo working paper no. $1081(2003)$.

[2] Betermier, S., Jansson, T., Parlour, C., and J. Walden, "Hedging labor income risk," Journal of Financial Economics 105:3 (2012), 622-639.

[3] Blanchard, O. J., and L. H. Summers, "Hysteresis and the European Unemployment Problem", in S. Fischer (Ed.), NBER Macroeconomics Annual (Cambridge, MA: MIT Press, 2006).

[4] Bodie, Z., R. C. Merton, and W. Samuelson, "Labor Supply Flexibility and Portfolio Choice in a Life-cycle Model," Journal of Economic Dynamics and Control 16:3-4 (1992), 427-449.

[5] Carroll, C. D., K. E. Dynan, and S. D. Krane, "Unemployment Risk and Precautionary Wealth: Evidence from Households' Balance Sheets," Review of Economics and Statistics 85:3 (2003), 586-604.

[6] Case, K. E., R. J. Shiller, and A. N. Weiss, "Index-Based Futures and Options Markets in Real Estate," Journal of Portfolio Management 19:2 (1993), 83-92.

[7] Cocco, J. F., "Portfolio Choice in the Presence of Housing," Review of Financial Studies $18: 2$ (2005), 535-567.

[8] Davidoff, T., "Labor Income, Housing Prices and Homeownership," Journal of Urban Economics 59:2 (2006), 209-235. 
[9] Dickens, W. T., L. Goette, E. L. Groshen, S. Holden, J. Messina, M. E. Schweitzer, J. Turunen, and M. E. Ward, "How Wages Change: Micro Evidence from the International Wage Flexibility Project," Journal of Economic Perspectives 21:2 (2007), 195-214.

[10] Duman, A., "Unemployment compensation in Sweden, Germany and United Kingdom: is there a tendency towards marketisation?" Central European University working paper (2005).

[11] Edin, P. A., and P. Fredriksson, "LINDA - Longitudinal Individual Data for Sweden," Mimeo, Uppsala University (2000).

[12] Festing, M., Y. Groening, R. Kabst, and W. Weber, "Financial Participation in Europe - Determinants and Outcomes," Economic and Industrial Democracy 20:2 (1999), 295329.

[13] Flavin, M., and T. Yamashita, "Owner-Occupied Housing and the Composition of the Household Portfolio Over the Life Cycle," American Economic Review 92:1 (2002), 345-362.

[14] Gathergood, J., "Unemployment risk, house price risk and the transition into home ownership in the United Kingdom," Journal of Housing Economics 20:3 (2011), 200209.

[15] Haurin, D., "Income variability, homeownership, and housing demand," Journal of Housing Economics 1:1 (1991), 60-74.

[16] Heaton, J., and D. Lucas, "Portfolio Choice in the Presence of Background Risk," Economic Journal 110 (2000), 1-26.

[17] Henderson, J. V., and Y. M. Ioannides, "A Model of Housing Tenure Choice," American Economic Review 73:1 (1983), 98-113. 
[18] Kemeny, J., From Public Housing to the Social Market: Rental Policy Strategies in Comparative Perspective (London, UK: Routledge, 1995).

[19] Massa, M., and A. Simonov, "Hedging, Familiarity, and Portfolio Choice," Review of Financial Studies 19:2 (2006), 633-685.

[20] Ortalo-Magné, F., and S. Rady, "Tenure choice and the riskiness of non-housing consumption," Journal of Housing Economics 11:3 (2002), 266-279.

[21] Sampford, M. R., "Some Inequalities on Mill's Ratio and Related Functions," Annals of Mathematical Statistics 24:1 (1953), 130-132.

[22] Shore, S. H., and T. Sinai, "Commitment, Risk, and Consumption: Do Birds of a Feather Have Bigger Nests?" Review of Economics and Statistics 92:2 (2010), 408-424.

[23] Sinai, T., and N. S. Souleles, "Owner-occupied housing as a hedge against rent risk," Quarterly Journal of Economics 120:2 (2005), 763-789.

[24] Statistics Sweden, Bostads- och byggnadsstatistisk årsbok 2006 (Statistics Sweden, 2006).

[25] Turner, T. M., "Does Investment Risk Affect the Housing Decisions of Families?" Economic Inquiry 41:4 (2003), 675-691.

[26] Yao, R., and H. H. Zhang, "Optimal consumption and portfolio choice with risky housing and stochastic labor income," Review of Financial Studies 18:1 (2005), 197-239. 
Table 1: Aggregate household wealth in Sweden

\begin{tabular}{lrrrr}
\hline \hline & \multicolumn{2}{c}{1999} & \multicolumn{3}{c}{2003} \\
\hline Real estate & 2,253 & $(56.3 \%)$ & 3,278 & $(68.8 \%)$ \\
Single-family homes & 1,347 & $(33.6 \%)$ & 1,984 & $(41.6 \%)$ \\
Cooperative apartments & 247 & $(6.2 \%)$ & 446 & $(9.4 \%)$ \\
Other real estate & 659 & $(16.5 \%)$ & 848 & $(17.8 \%)$ \\
Financial assets & 1,530 & $(38.2 \%)$ & 1,397 & $(29.3 \%)$ \\
Bank accounts & 365 & $(9.1 \%)$ & 458 & $(9.6 \%)$ \\
Mutual funds & 401 & $(10.0 \%)$ & 419 & $(8.8 \%)$ \\
Stocks & 517 & $(12.9 \%)$ & 328 & $(6.9 \%)$ \\
Other financial assets & 247 & $(6.2 \%)$ & 192 & $(4.0 \%)$ \\
Other assets & 222 & $(5.5 \%)$ & 89 & $(1.9 \%)$ \\
Total assets & 4,005 & $(100 \%)$ & 4,765 & $(100 \%)$ \\
Debt & 1,056 & & 1,477 & \\
Net wealth & 2,949 & & 3,288 & \\
\hline
\end{tabular}

Note: Values are reported in SEK billion. Percentages of total assets are shown in parentheses. The data are from Statistics Sweden. 
Table 2: Summary statistics

\begin{tabular}{|c|c|c|c|c|c|c|}
\hline & \multicolumn{2}{|c|}{ All households } & \multicolumn{4}{|c|}{ Married couples } \\
\hline & & & \multicolumn{2}{|c|}{ Spouse 1} & \multicolumn{2}{|c|}{ Spouse 2} \\
\hline & Mean & StdDev & Mean & StdDev & Mean & StdDev \\
\hline Home value & 868 & 1,025 & 1,254 & 1,096 & & \\
\hline Home value|homeowner & 1,311 & 1,003 & 1,469 & 1,045 & & \\
\hline Family size & 3 & 1 & 4 & 1 & & \\
\hline Age & 43 & 9 & 45 & 8 & 44 & 8 \\
\hline Household disposable income & 366 & 311 & 462 & 313 & & \\
\hline Individual disposable income & & & 266 & 290 & 172 & 62 \\
\hline Income as share of spouse 1's income & & & & & 0.71 & 0.20 \\
\hline $\operatorname{Cov}(p, \pi)$ & -0.00084 & 0.00076 & -0.00063 & 0.00057 & -0.00071 & 0.00059 \\
\hline$y \operatorname{Cov}(p, \pi)$ & -278 & 322 & -159 & 267 & -117 & 100 \\
\hline unemployment risk in 2003 & 0.10 & 0.07 & 0.07 & 0.05 & 0.09 & 0.06 \\
\hline$y \times$ unemployment risk in 2003 & 31,843 & 30,250 & 16,687 & 21,645 & 14,165 & 10,076 \\
\hline Average unemployment risk (1985-2003) & 0.10 & 0.08 & 0.07 & 0.05 & 0.09 & 0.06 \\
\hline$y \times$ average unemployment risk (1985-2003) & 31,060 & 28,783 & 15,451 & 19,237 & 13,716 & 9,661 \\
\hline Var(unemployment risk) & 0.00056 & 0.00071 & 0.00034 & 0.00049 & 0.00039 & 0.00054 \\
\hline$y \operatorname{Var}($ unemployment risk) & 171 & 235 & 79 & 146 & 61 & 81 \\
\hline$(1-\alpha)$ & 0.33 & 0.13 & & & & \\
\hline $\begin{array}{l}\text { Note: The samples are from the } 2003 \text { wave } \\
\text { and 45,205 of the married couples are classi } \\
\text { disposable income, home value is the marke } \\
\text { unemployment insurance benefits in case of } \\
\text { risks using data from the } 1985-2003 \text { waves } \\
\text { and incomes are reported in SEK thousand. }\end{array}$ & $\begin{array}{l}\text { JDA databa } \\
\text { meowners. } \\
\text { a househol } \\
\text { yment, Cov } \\
\text { NDA databa }\end{array}$ & $\begin{array}{l}=147,906 \\
\text { stands } \mathrm{f} \\
\text { vestment } \mathrm{i} \\
\text { s the cova } \\
\text { Statistics }\end{array}$ & $\begin{array}{l}\text { eholds) and } \\
\text { d deviation } \\
\text {-family hon } \\
\text { ween muni } \\
\text { and } y \text { is hou }\end{array}$ & $\begin{array}{l}8 \text { (married } \\
\text { se } 1 \text { is the } \\
-\alpha \text { ) is the } \\
\text { y homes } p \\
d \text { (individ }\end{array}$ & $\begin{array}{l}97,936 \text { of } \\
\text { ith the high } \\
\text { income not } \\
\text { individual } \\
\text { sable incom }\end{array}$ & $\begin{array}{l}\text { useholds } \\
\text { ported } \\
\text { ed by } \\
\text { loyment } \\
\text { me values }\end{array}$ \\
\hline
\end{tabular}


Table 3: Summary statistics

\begin{tabular}{|c|c|c|c|}
\hline & \multirow[t]{2}{*}{ All households } & \multicolumn{2}{|c|}{ Married couples } \\
\hline & & Spouse 1 & Spouse 2 \\
\hline Female & 0.38 & 0.25 & 0.75 \\
\hline Married & 0.56 & 1.00 & 1.00 \\
\hline Recent move (within 5 years) & 0.15 & 0.11 & 0.11 \\
\hline Recent civil status change (within 5 years) & 0.16 & 0.14 & 0.14 \\
\hline Age $26-30$ years & 0.09 & 0.03 & 0.04 \\
\hline Age $31-35$ years & 0.14 & 0.11 & 0.13 \\
\hline Age $36-40$ years & 0.19 & 0.19 & 0.20 \\
\hline Age $41-45$ years & 0.16 & 0.19 & 0.20 \\
\hline Age $46-50$ years & 0.15 & 0.19 & 0.19 \\
\hline Age $51-55$ years & 0.13 & 0.17 & 0.15 \\
\hline Age $56-60$ years & 0.13 & 0.12 & 0.09 \\
\hline Born in Sweden & 0.90 & 0.93 & 0.92 \\
\hline Born in other Nordic countries & 0.03 & 0.02 & 0.03 \\
\hline Born in EU15 + 6 OECD countries & 0.01 & 0.01 & 0.01 \\
\hline Born in all other countries & 0.06 & 0.04 & 0.05 \\
\hline Central government sector & 0.10 & 0.11 & 0.09 \\
\hline Local government sector & 0.25 & 0.21 & 0.45 \\
\hline Private sector & 0.65 & 0.68 & 0.46 \\
\hline Agriculture, hunting \& forestry & 0.01 & 0.01 & 0.01 \\
\hline Fishing & 0.00 & 0.00 & 0.00 \\
\hline Mining \& quarrying & 0.02 & 0.02 & 0.01 \\
\hline Manufacturing & 0.22 & 0.24 & 0.12 \\
\hline Electricity, gas \& water supply & 0.01 & 0.01 & 0.00 \\
\hline Construction & 0.08 & 0.09 & 0.03 \\
\hline Wholesale \& retail trade & 0.11 & 0.11 & 0.10 \\
\hline Hotels \& restaurants & 0.01 & 0.00 & 0.01 \\
\hline Transport \& communication & 0.07 & 0.07 & 0.04 \\
\hline Financial intermediation & 0.03 & 0.04 & 0.03 \\
\hline Real estate \& business activities & 0.09 & 0.10 & 0.07 \\
\hline Public administration \& defense & 0.03 & 0.04 & 0.02 \\
\hline Education, health \& social work & 0.30 & 0.25 & 0.52 \\
\hline Community \& personal services & 0.03 & 0.02 & 0.03 \\
\hline Employed in same industry & & \multicolumn{2}{|c|}{0.27} \\
\hline Employed in same sector & & \multicolumn{2}{|c|}{0.46} \\
\hline Employed in same industry \& same sector & & \multicolumn{2}{|c|}{0.22} \\
\hline
\end{tabular}

Note: This table shows mean values of characteristic indicator variables. The samples are from the 2003 wave of the LINDA database. $N=147,906$ (all households) and 52,928 (married couples).

Spouse 1 is the spouse with the highest reported disposable income. 
Table 4: Share of households by type of building and tenure

\begin{tabular}{lcccccc}
\hline \hline Type of building & $\begin{array}{c}\text { Number of } \\
\text { households } \\
\text { (thousands) }\end{array}$ & $\begin{array}{c}\text { Home- } \\
\text { owners }\end{array}$ & $\begin{array}{c}\text { Co-op } \\
\text { share } \\
\text { owners }\end{array}$ & Renters & Others & N/A \\
\hline Total & 3,830 & $41 \%$ & $15 \%$ & $40 \%$ & $4 \%$ & $1 \%$ \\
$\begin{array}{l}\text { One- or two- } \\
\text { dwelling buildings }\end{array}$ & 1,861 & $82 \%$ & $3 \%$ & $11 \%$ & $4 \%$ & $0 \%$ \\
$\begin{array}{l}\text { Three- or more } \\
\text { dwelling buildings }\end{array}$ & 1,969 & $2 \%$ & $26 \%$ & $67 \%$ & $4 \%$ & $2 \%$ \\
\hline
\end{tabular}

Note: The data are from the latest census in Sweden (1990). Co-op share refers to a share in a cooperative housing association. Source: Bostads- och byggnadsstatistik årsbok (2006), Statistics Sweden. 
Table 5: Empirical results of annual probit regressions on employment status

\begin{tabular}{|c|c|c|c|c|c|c|c|}
\hline & $\begin{array}{l}\text { (1985) } \\
\text { Unemployed }\end{array}$ & $\begin{array}{l}\text { (1988) } \\
\text { Unemployed }\end{array}$ & $\begin{array}{l}\text { (1991) } \\
\text { Unemployed }\end{array}$ & $\begin{array}{l}\text { (1994) } \\
\text { Unemployed }\end{array}$ & $\begin{array}{l}\text { (1997) } \\
\text { Unemployed }\end{array}$ & $\begin{array}{l}(2000) \\
\text { Unemployed }\end{array}$ & $\begin{array}{c}\text { (2003) } \\
\text { Unemployed }\end{array}$ \\
\hline \multirow[t]{2}{*}{ Female } & $0.015 * * *$ & $0.021 * * *$ & $0.012 * * *$ & $0.019 * * *$ & $0.048 * * *$ & $0.049 * * *$ & $0.030 * * *$ \\
\hline & {$[0.001]$} & {$[0.001]$} & {$[0.001]$} & {$[0.002]$} & {$[0.002]$} & {$[0.001]$} & {$[0.001]$} \\
\hline \multirow[t]{2}{*}{ Married } & $-0.025 * * *$ & $-0.023 * * *$ & $-0.028 * * *$ & $-0.042 * * *$ & $-0.043^{* * *}$ & $-0.038 * * *$ & $-0.031 * * *$ \\
\hline & {$[0.001]$} & {$[0.001]$} & {$[0.001]$} & {$[0.001]$} & {$[0.001]$} & {$[0.001]$} & {$[0.001]$} \\
\hline \multirow[t]{2}{*}{ Age $31-35$ years } & $-0.011 * * *$ & $-0.012 * * *$ & $-0.016 * * *$ & $-0.041 * * *$ & $-0.035 * * *$ & $-0.022 * * *$ & $-0.012 * * *$ \\
\hline & {$[0.001]$} & {$[0.001]$} & {$[0.001]$} & {$[0.002]$} & {$[0.002]$} & {$[0.002]$} & {$[0.002]$} \\
\hline \multirow[t]{2}{*}{ Age $36-40$ years } & $-0.016 * * *$ & $-0.018 * * *$ & $-0.025 * * *$ & $-0.068 * * *$ & $-0.064 * * *$ & $-0.040 * * *$ & $-0.028 * * *$ \\
\hline & {$[0.001]$} & {$[0.001]$} & {$[0.001]$} & {$[0.002]$} & {$[0.002]$} & {$[0.002]$} & {$[0.002]$} \\
\hline \multirow[t]{2}{*}{ Age $41-45$ years } & $-0.019 * * *$ & $-0.021 * * *$ & $-0.034 * * *$ & $-0.083 * * *$ & $-0.080 * * *$ & $-0.055 * * *$ & $-0.040 * * *$ \\
\hline & {$[0.001]$} & {$[0.001]$} & {$[0.001]$} & {$[0.002]$} & {$[0.002]$} & {$[0.001]$} & {$[0.002]$} \\
\hline \multirow[t]{2}{*}{ Age $46-50$ years } & $-0.020 * * *$ & $-0.023 * * *$ & $-0.038 * * *$ & $-0.098 * * *$ & $-0.093 * * *$ & $-0.064 * * *$ & $-0.050 * * *$ \\
\hline & {$[0.001]$} & {$[0.001]$} & {$[0.001]$} & {$[0.001]$} & {$[0.001]$} & {$[0.001]$} & {$[0.001]$} \\
\hline \multirow[t]{2}{*}{ Age $51-55$ years } & $-0.021 * * *$ & $-0.022 * * *$ & $-0.037 * * *$ & $-0.102 * * *$ & $-0.098 * * *$ & $-0.066 * * *$ & $-0.055 * * *$ \\
\hline & {$[0.001]$} & {$[0.001]$} & {$[0.001]$} & {$[0.001]$} & {$[0.001]$} & {$[0.001]$} & {$[0.001]$} \\
\hline \multirow[t]{2}{*}{ Age $56-60$ years } & $-0.021 * * *$ & $-0.023 * * *$ & $-0.037 * * *$ & $-0.107 * * *$ & $-0.095 * * *$ & $-0.057 * * *$ & $-0.051 * * *$ \\
\hline & {$[0.001]$} & {$[0.001]$} & {$[0.001]$} & {$[0.001]$} & {$[0.001]$} & {$[0.002]$} & {$[0.002]$} \\
\hline \multirow[t]{2}{*}{ Born in other Nordic countries } & $0.022 * * *$ & $0.018 * * *$ & $0.026 * * *$ & $0.043 * * *$ & $0.035 * * *$ & $0.036 * * *$ & $0.026 * * *$ \\
\hline & {$[0.003]$} & {$[0.002]$} & {$[0.002]$} & [0.004] & [0.004] & [0.004] & [0.004] \\
\hline \multirow[t]{2}{*}{ Born in EU15 + 6 OECD countries } & $0.034 * * *$ & $0.023 * * *$ & $0.032 * * *$ & $0.051 * * *$ & $0.049 * * *$ & $0.038 * * *$ & $0.029 * * *$ \\
\hline & {$[0.005]$} & {$[0.005]$} & {$[0.005]$} & [0.007] & [0.007] & [0.007] & {$[0.006]$} \\
\hline \multirow[t]{2}{*}{ Born in all other countries } & $0.061 * * *$ & $0.062 * * *$ & $0.089 * * *$ & $0.169 * * *$ & $0.208 * * *$ & $0.169 * * *$ & $0.106 * * *$ \\
\hline & {$[0.005]$} & {$[0.004]$} & {$[0.003]$} & {$[0.004]$} & [0.004] & {$[0.004]$} & [0.003] \\
\hline \multirow[t]{2}{*}{ Local government sector } & $0.010 * * *$ & $0.005 * * *$ & 0.003 & -0.002 & 0.002 & $0.017 * * *$ & 0.004 \\
\hline & {$[0.002]$} & {$[0.002]$} & {$[0.002]$} & {$[0.003]$} & [0.003] & {$[0.003]$} & [0.003] \\
\hline \multirow[t]{2}{*}{ Private sector } & $0.016 * * *$ & $0.009 * * *$ & $0.015 * * *$ & $0.053 * * *$ & $0.050 * * *$ & $0.040 * * *$ & $0.029 * * *$ \\
\hline & {$[0.002]$} & {$[0.001]$} & {$[0.002]$} & [0.002] & [0.003] & {$[0.002]$} & {$[0.002]$} \\
\hline \multirow[t]{2}{*}{ Fishing } & $0.203 * *$ & $0.088 *$ & $0.222 * * *$ & -0.005 & 0.029 & $0.070 * * *$ & 0.022 \\
\hline & {$[0.088]$} & {$[0.046]$} & {$[0.065]$} & {$[0.021]$} & {$[0.021]$} & {$[0.024]$} & {$[0.018]$} \\
\hline \multirow[t]{2}{*}{ Mining \& quarrying } & $-0.029 * * *$ & $-0.028 * * *$ & $-0.032 * * *$ & $-0.057 * * *$ & $-0.054 * * *$ & $-0.053 * * *$ & $-0.040 * * *$ \\
\hline & {$[0.002]$} & {$[0.001]$} & {$[0.003]$} & {$[0.005]$} & {$[0.005]$} & {$[0.004]$} & {$[0.004]$} \\
\hline
\end{tabular}


Table 5 (cont.)

\begin{tabular}{|c|c|c|c|c|c|c|c|}
\hline & $\begin{array}{l}\text { (1985) } \\
\text { Unemployed }\end{array}$ & $\begin{array}{l}\text { (1988) } \\
\text { Unemployed }\end{array}$ & $\begin{array}{l}\text { (1991) } \\
\text { Unemployed }\end{array}$ & $\begin{array}{l}\text { (1994) } \\
\text { Unemployed }\end{array}$ & $\begin{array}{l}\text { (1997) } \\
\text { Unemployed }\end{array}$ & $\begin{array}{l}(2000) \\
\text { Unemployed }\end{array}$ & $\begin{array}{l}\text { (2003) } \\
\text { Unemployed }\end{array}$ \\
\hline \multirow[t]{2}{*}{ Manufacturing } & $-0.039 * * *$ & $-0.035 * * *$ & $-0.038 * * *$ & $-0.101 * * *$ & $-0.105 * * *$ & $-0.075 * * *$ & $-0.067 * * *$ \\
\hline & {$[0.002]$} & {$[0.001]$} & {$[0.002]$} & {$[0.003]$} & {$[0.003]$} & {$[0.003]$} & {$[0.003]$} \\
\hline \multirow[t]{2}{*}{ Electricity, gas \& water supply } & $-0.031 * * *$ & $-0.029 * * *$ & $-0.045 * * *$ & $-0.112 * * *$ & $-0.104 * * *$ & $-0.086^{* * *}$ & $-0.073 * * *$ \\
\hline & {$[0.001]$} & {$[0.001]$} & {$[0.001]$} & {$[0.003]$} & {$[0.003]$} & {$[0.003]$} & {$[0.003]$} \\
\hline \multirow[t]{2}{*}{ Construction } & $0.011 * * *$ & $-0.011 * * *$ & $-0.015 * * *$ & $0.012 * *$ & $0.014 * *$ & -0.007 & $-0.015 * * *$ \\
\hline & {$[0.004]$} & {$[0.002]$} & {$[0.003]$} & {$[0.006]$} & {$[0.006]$} & {$[0.005]$} & {$[0.004]$} \\
\hline \multirow[t]{2}{*}{ Wholesale \& retail trade } & $-0.027 * * *$ & $-0.023 * * *$ & $-0.024 * * *$ & $-0.054 * * *$ & $-0.053 * * *$ & $-0.033 * * *$ & $-0.024 * * *$ \\
\hline & {$[0.002]$} & {$[0.001]$} & {$[0.002]$} & {$[0.004]$} & {$[0.004]$} & {$[0.004]$} & {$[0.004]$} \\
\hline \multirow[t]{2}{*}{ Hotels \& restaurants } & -0.005 & -0.005 & $0.008 *$ & $0.029 * * *$ & $0.016 * *$ & 0.010 & $0.014 * *$ \\
\hline & {$[0.004]$} & {$[0.003]$} & {$[0.004]$} & {$[0.008]$} & {$[0.008]$} & {$[0.007]$} & {$[0.007]$} \\
\hline \multirow[t]{2}{*}{ Transport, storage \& communication } & $-0.027 * * *$ & $-0.027 * * *$ & $-0.028 * * *$ & $-0.060 * * *$ & $-0.050 * * *$ & $-0.032 * * *$ & $-0.034 * * *$ \\
\hline & {$[0.001]$} & {$[0.001]$} & {$[0.002]$} & {$[0.004]$} & {$[0.004]$} & {$[0.004]$} & {$[0.003]$} \\
\hline \multirow[t]{2}{*}{ Financial intermediation } & $-0.033 * * *$ & $-0.031 * * *$ & $-0.031 * * *$ & $-0.051 * * *$ & $-0.072 * * *$ & $-0.066^{* * *}$ & $-0.062 * * *$ \\
\hline & {$[0.001]$} & {$[0.001]$} & {$[0.002]$} & {$[0.004]$} & {$[0.003]$} & {$[0.003]$} & {$[0.002]$} \\
\hline \multirow[t]{2}{*}{ Real estate $\&$ business activities } & $-0.023 * * *$ & $-0.023 * * *$ & $-0.023 * * *$ & $-0.017 * * *$ & $-0.029 * * *$ & $-0.024 * * *$ & $-0.013 * * *$ \\
\hline & {$[0.002]$} & {$[0.001]$} & {$[0.002]$} & {$[0.005]$} & {$[0.004]$} & {$[0.004]$} & {$[0.004]$} \\
\hline \multirow[t]{2}{*}{ Public administration \& defense } & $-0.013 * * *$ & $-0.023 * * *$ & $0.010 * *$ & $-0.064 * * *$ & $-0.068 * * *$ & $-0.061 * * *$ & $-0.057 * * *$ \\
\hline & {$[0.003]$} & {$[0.001]$} & {$[0.004]$} & {$[0.005]$} & {$[0.004]$} & {$[0.004]$} & {$[0.003]$} \\
\hline \multirow[t]{2}{*}{ Education, health \& social work } & $-0.023 * * *$ & $-0.020 * * *$ & -0.005 & $0.022 * * *$ & $0.022 * * *$ & $0.008 *$ & 0.003 \\
\hline & {$[0.002]$} & {$[0.003]$} & {$[0.003]$} & {$[0.005]$} & {$[0.005]$} & {$[0.005]$} & {$[0.005]$} \\
\hline \multirow{2}{*}{$\begin{array}{l}\text { Community, social \& personal } \\
\text { services }\end{array}$} & $-0.016 * * *$ & $-0.016^{* * *}$ & $-0.009 * * *$ & $-0.029 * * *$ & $-0.009 *$ & -0.003 & -0.005 \\
\hline & {$[0.002]$} & {$[0.002]$} & {$[0.003]$} & {$[0.005]$} & {$[0.005]$} & {$[0.005]$} & {$[0.005]$} \\
\hline Observations & 203,349 & 232,019 & 300,220 & 293,076 & 291,745 & 288,627 & 288,184 \\
\hline Share of unemployed & 0.0499 & 0.0462 & 0.0637 & 0.154 & 0.152 & 0.126 & 0.107 \\
\hline Log likelihood & $-35,981$ & $-38,888$ & $-64,850$ & $-114,117$ & $-110,145$ & $-96,515$ & $-89,637$ \\
\hline
\end{tabular}

Note: The samples are from the annual waves of the LINDA database, 1985 through 2003. The dependent variable, unemployed, indicates whether public unemployment benefits are received. Marginal effects (evaluated at the mean) from the probit regressions for every third year are reported. Standard errors are shown in square brackets. * denotes significance at $10 \%, * *$ at $5 \%$ and $* * *$ at $1 \%$. The base group is male, unmarried, 26-30 years of age, born in Sweden, works in the agriculture, hunting and forestry industry and is employed by the central government. Indicator variables for A-regions (local labor markets) and education are included in all regressions but are not reported here. See Appendix A.2 for descriptions of the explanatory variables. 
Table 6: Sample distributions of covariance and correlation estimates between individual unemployment risks and local home prices by tenure, sector and industry

\begin{tabular}{|c|c|c|c|c|c|c|c|c|}
\hline & \multicolumn{4}{|c|}{$\operatorname{Cov}(p, \pi)($ multiplied by 100$)$} & \multicolumn{4}{|c|}{$\operatorname{Corr}(p, \pi)$} \\
\hline & Mean & StdDev & Min & Max & Mean & StdDev & Min & Max \\
\hline All observations & -0.084 & 0.076 & -0.686 & 0.543 & -0.50 & 0.20 & -0.91 & 0.61 \\
\hline \multicolumn{9}{|l|}{ By tenure } \\
\hline Renters & -0.116 & 0.092 & -0.686 & 0.295 & -0.55 & 0.19 & -0.91 & 0.48 \\
\hline Homeowners & -0.068 & 0.061 & -0.620 & 0.543 & -0.47 & 0.20 & -0.91 & 0.61 \\
\hline \multicolumn{9}{|l|}{ By sector } \\
\hline Central government sector & -0.050 & 0.060 & -0.529 & 0.133 & -0.38 & 0.26 & -0.90 & 0.53 \\
\hline Local government sector & -0.079 & 0.067 & -0.569 & 0.262 & -0.55 & 0.20 & -0.90 & 0.53 \\
\hline Private sector & -0.092 & 0.080 & -0.686 & 0.543 & -0.49 & 0.19 & -0.91 & 0.61 \\
\hline \multicolumn{9}{|l|}{ By industry } \\
\hline Agriculture, hunting \& forestry & -0.051 & 0.056 & -0.355 & 0.192 & -0.22 & 0.19 & -0.67 & 0.44 \\
\hline Fishing & 0.058 & 0.125 & -0.196 & 0.543 & 0.11 & 0.18 & -0.24 & 0.61 \\
\hline Mining \& quarrying & -0.071 & 0.049 & -0.378 & 0.036 & -0.48 & 0.16 & -0.79 & 0.21 \\
\hline Manufacturing & -0.044 & 0.037 & -0.388 & 0.189 & -0.39 & 0.17 & -0.80 & 0.55 \\
\hline Electricity, gas \& water supply & -0.015 & 0.015 & -0.141 & 0.027 & -0.35 & 0.17 & -0.81 & 0.28 \\
\hline Construction & -0.151 & 0.085 & -0.641 & 0.084 & -0.55 & 0.15 & -0.89 & 0.36 \\
\hline Wholesale \& retail trade & -0.082 & 0.062 & -0.470 & 0.123 & -0.51 & 0.17 & -0.88 & 0.45 \\
\hline Hotels \& restaurants & -0.168 & 0.108 & -0.565 & 0.138 & -0.53 & 0.16 & -0.82 & 0.25 \\
\hline Transport, storage \& communication & -0.081 & 0.061 & -0.501 & 0.078 & -0.55 & 0.18 & -0.90 & 0.34 \\
\hline Financial intermediation & -0.081 & 0.057 & -0.513 & 0.059 & -0.53 & 0.14 & -0.79 & 0.35 \\
\hline Real estate \& business activities & -0.138 & 0.089 & -0.686 & 0.107 & -0.61 & 0.15 & -0.91 & 0.27 \\
\hline Public administration \& defense & -0.009 & 0.031 & -0.266 & 0.133 & -0.12 & 0.21 & -0.73 & 0.53 \\
\hline Education, health \& social work & -0.089 & 0.075 & -0.637 & 0.262 & -0.55 & 0.19 & -0.90 & 0.49 \\
\hline Community, social \& personal services & -0.123 & 0.090 & -0.532 & 0.136 & -0.56 & 0.19 & -0.85 & 0.32 \\
\hline
\end{tabular}

Note: The sample is from the 2003 wave of the LINDA database. $N=147,906$. $\operatorname{Cov}(p, \pi)$ and $\operatorname{Corr}(p, \pi)$ are the estimated covariance and correlation

coefficients between individual unemployment risks and local single-family home prices using data from the 1985-2003 waves of the LINDA database and Statistics Sweden. StdDev stands for standard deviation. The reported $\operatorname{Cov}(p, \pi)$ estimates are multiplied by 100. 
Table 7: Average correlation estimates between individual unemployment risks and local home prices by region and industry

\begin{tabular}{llrc}
\hline \hline A-region & Industry & $\begin{array}{c}\text { No. of } \\
\text { obs. }\end{array}$ & $\begin{array}{c}\text { Average } \\
\text { correlation }\end{array}$ \\
\hline Panel A: Lowest average correlations & & \\
\hline Kristianstad & Real estate \& business activities & 113 & -0.7206 \\
Enköping & Real estate \& business activities & 109 & -0.7181 \\
Enköping & Construction & 142 & -0.7089 \\
Örebro & Real estate \& business activities & 241 & -0.6987 \\
Norrköping & Real estate \& business activities & 219 & -0.6941 \\
Enköping & Transport, storage \& communication & 77 & -0.6880 \\
Enköping & Wholesale \& retail trade & 150 & -0.6822 \\
Eskilstuna & Education, health \& social work & 606 & -0.6821 \\
Visby & Construction & 77 & -0.6803 \\
Enköping & Community, social \& personal services & 26 & -0.6785 \\
Stockholm/Södertälje & Real estate \& business activities & 4,178 & -0.6761 \\
Eskilstuna & Real estate \& business activities & 188 & -0.6757 \\
Eskilstuna & Community, social \& personal services & 48 & -0.6747 \\
Örnsköldsvik & Mining \& quarrying & 23 & -0.6726 \\
Visby & Education, health \& social work & 392 & -0.6723 \\
\hline
\end{tabular}

Panel B: Highest average correlations

\begin{tabular}{llrl}
\hline Härnösand/Kramfors & Public administration \& defense & 25 & 0.1387 \\
Sundsvall & Public administration \& defense & 55 & 0.1149 \\
Karlskrona & Public administration \& defense & 146 & 0.1136 \\
Köping & Public administration \& defense & 27 & 0.1106 \\
Kiruna/Gällivare & Public administration \& defense & 21 & 0.1082 \\
Karlshamn & Public administration \& defense & 31 & 0.0922 \\
Göteborg & Fishing & 25 & 0.0905 \\
Gävle/Sandviken & Public administration \& defense & 49 & 0.0766 \\
Skövde & Public administration \& defense & 85 & 0.0623 \\
Nyköping & Public administration \& defense & 40 & 0.0577 \\
Karlstad & Public administration \& defense & 85 & 0.0530 \\
Örebro & Public administration \& defense & 91 & 0.0470 \\
Halmstad & Public administration \& defense & 102 & 0.0423 \\
Kalmar/Nybro & Public administration \& defense & 45 & 0.0405 \\
Eksjö/Nässjö/Vetlanda & Public administration \& defense & 55 & 0.0091 \\
\hline
\end{tabular}

Note: A-region is a local labor market. Groups containing fewer than 20 individuals are not included. 
Table 8: Pearson correlation coefficients of various unemployment risk measures between spouses

\begin{tabular}{lcc}
\hline \hline & Same sector & Different sectors \\
\hline Unemployment & $0.168^{* * * *}$ & $0.136^{* * * *}$ \\
Same industry & $0.073^{* * *}$ & $0.074^{* * *}$ \\
Different industries & & \\
& & \\
Unemployment risk in 2003 & $0.587^{* * *}$ & $0.426^{* * *}$ \\
Same industry & $0.321^{* * *}$ & $0.373^{* * *}$ \\
Different industries & & \\
Cov(p, $\pi)$ & $0.723^{* * *}$ & $0.517^{* * *}$ \\
Same industry & $0.377^{* * *}$ & $0.424^{* * *}$ \\
Different industries & & \\
\hline
\end{tabular}

Note: The sample of married couples is from the 2003 wave of the LINDA database including married couples in which one or both of the spouses receive unemployment benefits. $N=62,221$. $* * *$ denotes significance at $1 \%$. Unemployment refers to actual payments of unemployment insurance benefits and $\operatorname{Cov}(p, \pi)$ is the estimated covariance between individual unemployment risks and local home prices using data from the 1985-2003 waves of the LINDA database and Statistics Sweden. Sectors and industries are described in Appendix A.2. 
Table 9: Homeownership probabilities

\begin{tabular}{|c|c|c|c|c|c|}
\hline \multicolumn{6}{|c|}{ Probability of homeownership (single-family home) } \\
\hline \multicolumn{6}{|c|}{ Income quartile } \\
\hline & All & 1 & 2 & 3 & 4 \\
\hline \multicolumn{6}{|c|}{ Panel A: Average municipality single-family home value below SEK 856,220 } \\
\hline $\operatorname{Cov}(p, \pi)>$ median & 0.83 & 0.54 & 0.85 & 0.92 & 0.94 \\
\hline $\operatorname{Cov}(p, \pi)<$ median & 0.72 & 0.43 & 0.79 & 0.89 & 0.92 \\
\hline \multicolumn{6}{|c|}{ Panel B: Average municipality single-family home value SEK $856,220-1,228,677$} \\
\hline $\operatorname{Cov}(p, \pi)>$ median & 0.79 & 0.44 & 0.77 & 0.88 & 0.92 \\
\hline $\operatorname{Cov}(p, \pi)<$ median & 0.63 & 0.31 & 0.66 & 0.84 & 0.88 \\
\hline \multicolumn{6}{|c|}{ Panel C: Average municipality single-family home value SEK 1,228,677-1,991,269 } \\
\hline $\operatorname{Cov}(p, \pi)>$ median & 0.76 & 0.35 & 0.68 & 0.84 & 0.90 \\
\hline $\operatorname{Cov}(p, \pi)<$ median & 0.56 & 0.23 & 0.55 & 0.76 & 0.85 \\
\hline \multicolumn{6}{|c|}{ Panel D: Average municipality single-family home value above SEK 1,991,269 } \\
\hline $\operatorname{Cov}(p, \pi)>$ median & 0.67 & 0.27 & 0.52 & 0.69 & 0.83 \\
\hline $\operatorname{Cov}(p, \pi)<$ median & 0.40 & 0.12 & 0.34 & 0.58 & 0.77 \\
\hline
\end{tabular}

Note: This table shows homeownership probabilities sorted by the average value of single-family homes in the municipality of residence, income quartiles and the covariance between individual unemployment risks and local home prices. 97,936 out of 147,906 households in the sample are homeowners. $\operatorname{Cov}(p, \pi)$ is the estimated covariance between individual unemployment risks and local single-family home prices of the individual with the highest reported income in the household. The median value of $\operatorname{Cov}(p, \pi)$ in the sample is $-6.35 \mathrm{e}-04$. Household disposable income in the first quartile is below SEK 246,470, in the second quartile between SEK 246,470 and 349,445 and in the fourth quartile above SEK 438,525. 
Table 10: Empirical results of regressions on homeownership and on the value of household investments in single-family homes

\begin{tabular}{|c|c|c|c|c|c|c|c|c|}
\hline \multirow{4}{*}{$\begin{array}{l}\text { Dependent variable: } \\
\text { Sample: } \\
\text { Regression model: }\end{array}$} & (1) & (2) & (3) & (4) & $(5)$ & $(6)$ & (7) & $(8)$ \\
\hline & \multirow{2}{*}{\multicolumn{2}{|c|}{$\begin{array}{l}\text { Homeowner } \\
\text { Full sample }\end{array}$}} & \multirow{2}{*}{\multicolumn{2}{|c|}{$\begin{array}{l}\text { Home value } \\
\text { Full sample }\end{array}$}} & \multirow{2}{*}{\multicolumn{2}{|c|}{$\begin{array}{c}\text { Home value } \\
\text { Homeowners }\end{array}$}} & \multicolumn{2}{|c|}{ Home value } \\
\hline & & & & & & & Full sample & Homeowners \\
\hline & Probit & Probit & OLS & OLS & OLS & OLS & Tobit & Heckman \\
\hline$y \operatorname{Cov}(p, \pi)$ & $\begin{array}{c}-0.35 \\
{[1.36]}\end{array}$ & $\begin{array}{l}9.15^{* * *} \\
{[1.57]}\end{array}$ & $\begin{array}{l}298 * * * \\
{[35]}\end{array}$ & $\begin{array}{l}331 * * * \\
{[23]}\end{array}$ & $\begin{array}{l}146^{* * * *} \\
{[34]}\end{array}$ & $\begin{array}{l}184 * * * \\
{[25]}\end{array}$ & $\begin{array}{l}373 * * * \\
{[25]}\end{array}$ & $\begin{array}{l}145^{* * * *} \\
{[32]}\end{array}$ \\
\hline $\mathbf{Z} \times$ income controls? & No & Yes & No & Yes & No & Yes & Yes & Yes/No \\
\hline Adj. $R^{2} /$ Log likelihood & $-65,076$ & $-64,589$ & 0.427 & 0.433 & 0.575 & 0.579 & $-1.53 e+06$ & $-1.51 \mathrm{e}+06$ \\
\hline Number of observations & 147,906 & 147,906 & 147,906 & 147,906 & 97,936 & 97,936 & 147,906 & $147,906 / 97,936$ \\
\hline
\end{tabular}

Note: Homeowner indicates ownership of a single-family home and home value is the market value of household investments in single-family homes. Robust (in specifications (3) to (6) bootstrap) standard errors are shown in square brackets. * denotes significance at 10\%, ** at 5\% and *** at $1 \%$. Marginal effects evaluated at the mean are reported in specifications (1), (2) and (7). Reported coefficient estimates are multiplied by 10e5 in specifications (1) and (2). The Heckman two-step selection model in specification (8) is estimated using full maximum likelihood, and lambda is $-53,980$ with a standard error of 11,805. $\operatorname{Cov}(p, \pi)$ is the estimated covariance between individual unemployment risks and local single-family home prices and $y$ is household disposable income. The $\mathbf{Z}$ vector of demographic controls includes family size and indicator variables for age group, country of birth, education, gender, marital status, sector and industry. All regressions include the $\mathbf{Z}$ vector of demographic controls, indicator variables for the municipality of residence, moves and civil status changes within the last five years, and interaction variables between income squared and the municipality of residence and between income and the following variables: municipality of residence, unemployment risk in 2003, average unemployment risk (1985-2003) and unemployment risk variance. The explanatory variables are described in Appendix A.2. All amounts are in Swedish kronor (SEK). 
Table 11: Empirical results of regressions on married couples’ homeownership and investments in single-family homes

\begin{tabular}{|c|c|c|c|c|c|c|}
\hline & $(1)$ & $(2)$ & $(3)$ & $(4)$ & $(5)$ & $(6)$ \\
\hline Dependent variable: & Homeowner & Homeowner & Homeowner & Home value & Home value & Home value \\
\hline \multirow[t]{2}{*}{$y \operatorname{Cov}(p, \pi)$ Spouse 1} & $7.26 * * *$ & $7.36 * * *$ & $7.38 * * *$ & $254 * * *$ & $256 * *$ & $254 * * *$ \\
\hline & {$[2.790]$} & {$[2.793]$} & [2.794] & [70] & {$[100]$} & [87] \\
\hline \multirow[t]{2}{*}{$y \operatorname{Cov}(p, \pi)$ Spouse 2} & 5.52 & 5.53 & 5.53 & 0 & 10 & 13 \\
\hline & [3.893] & [3.896] & [3.896] & [92] & {$[100]$} & [88] \\
\hline \multirow[t]{2}{*}{ Same industry } & & $-0.01 * *$ & -0.01 & & $66,727 * * *$ & $-2,098$ \\
\hline & & [0.004] & {$[0.007]$} & & {$[8,411]$} & {$[17,757]$} \\
\hline \multirow[t]{2}{*}{ Same sector } & & & -0.00 & & & $-47,358 * * *$ \\
\hline & & & {$[0.004]$} & & & {$[5,885]$} \\
\hline \multirow{2}{*}{$\begin{array}{l}\text { Same industry \& } \\
\text { same sector }\end{array}$} & & & 0.00 & & & $109,701 * * *$ \\
\hline & & & [0.008] & & & {$[17,398]$} \\
\hline $\mathbf{Z} \times$ income controls? & Yes & Yes & Yes & No & No & No \\
\hline Adj. $R^{2} /$ Log likelihood & $-17,536$ & $-17,533$ & $-17,532$ & 0.597 & 0.597 & 0.597 \\
\hline Number of obs. & 52,665 & 52,665 & 52,665 & 45,205 & 45,205 & 45,205 \\
\hline
\end{tabular}

Note: Married couples only. Homeowner indicates ownership of a single-family home and home value is the market value of household investments in single-family homes. Robust (in specifications (4) to (6) bootstrap) standard errors are shown in square brackets. $*$ denotes significance at $10 \%$, ** at $5 \%$ and $* * *$ at $1 \%$. Marginal effects (multiplied by 10e5) evaluated at the mean are reported in specifications (1) to (3). 263 observations are dropped in specifications (1) to (3) since homeownership is perfectly predicted. $\operatorname{Cov}(p, \pi)$ is the estimated covariance between individual unemployment risks and local single-family home prices, $y$ is disposable income, spouse 1 is the spouse with the highest reported disposable income, and same industry (sector) is a variable that indicates whether both spouses work in the same industry (sector). The $\mathbf{Z}$ vector of demographic controls includes family size and indicator variables for age group, country of birth, education, gender, marital status, sector and industry. All regressions include spouse 2's income as a percentage of spouse 1's income and, for each spouse, the $\mathbf{Z}$ vector of demographic controls, indicator variables for the municipality of residence, moves and civil status changes within the last five years, and interaction variables between individual income and the following variables: unemployment risk in 2003, average unemployment risk (1985-2003) and unemployment risk variance. Interaction variables between municipality of residence and income and income squared are included in specifications (4) to (6). The explanatory variables are described in Appendix A.2. All amounts are in Swedish kronor (SEK). 
Table 12: Average household investments in single-family homes

\begin{tabular}{|c|c|c|c|c|}
\hline & \multicolumn{2}{|c|}{ Home value } & \multicolumn{2}{|c|}{ Home value } \\
\hline & \multicolumn{2}{|c|}{ All households } & \multicolumn{2}{|c|}{ Homeowners only } \\
\hline & Mean & Median & Mean & Median \\
\hline \multicolumn{5}{|c|}{ Panel A: Average municipality single-family home value below SEK 856,220 } \\
\hline $\operatorname{Cov}(p, \pi)>$ median & 527 & 519 & 636 & 587 \\
\hline $\operatorname{Cov}(p, \pi)<$ median & 450 & 454 & 623 & 581 \\
\hline \multicolumn{5}{|c|}{ Panel B: Average municipality single-family home value SEK 856,220-1,228,677 } \\
\hline $\operatorname{Cov}(p, \pi)>$ median & 843 & 860 & 1,068 & 990 \\
\hline $\operatorname{Cov}(p, \pi)<$ median & 624 & 641 & 994 & 938 \\
\hline
\end{tabular}

Panel C: Average municipality single-family home value SEK 1,228,677-1,991,269

\begin{tabular}{lcccc}
\hline $\operatorname{Cov}(p, \pi)>$ median & 1,254 & 1,284 & 1,647 & 1,509 \\
$\operatorname{Cov}(p, \pi)<$ median & 822 & 711 & 1,476 & 1,366 \\
\hline
\end{tabular}

Panel D: Average municipality single-family home value above SEK 1,991,269

\begin{tabular}{lcccc}
\hline $\operatorname{Cov}(p, \pi)>$ median & 1,718 & 1,712 & 2,573 & 2,283 \\
$\operatorname{Cov}(p, \pi)<$ median & 920 & 0 & 2,287 & 2,043 \\
\hline
\end{tabular}

Note: This table shows average household investments in single-family homes sorted by the average value of single-family homes in the municipality of residence and the covariance between individual unemployment risks and local home prices. $N=147,906$ (all households) and 97,936 (homeowners). Home value is the market value of a household's investment in a single-family home and is reported in SEK thousand. $\operatorname{Cov}(p, \pi)$ is the estimated covariance between individual unemployment risks and local single-family home prices of the individual with the highest reported disposable income in the household. The median value of $\operatorname{Cov}(p, \pi)$ in the sample is $-6.35 \mathrm{e}-04$. 
Table 13: Share of households that are renters and average value of household covariance between unemployment risks and local home prices among same- and different industry couples

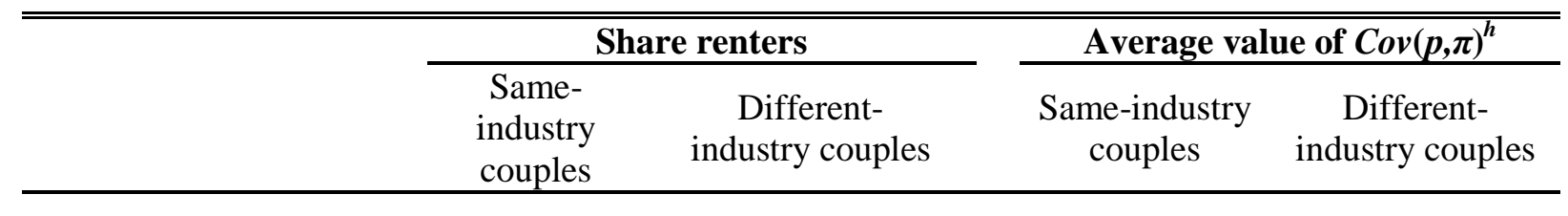

\section{Panel A: All married couples}

\begin{tabular}{lllll}
\hline All sectors & 0.16 & 0.14 & -250 & -268 \\
Central government & 0.18 & 0.13 & -131 & -150 \\
Local government & 0.15 & 0.15 & -193 & -186 \\
Private sector & 0.16 & 0.16 & -299 & -353 \\
\hline
\end{tabular}

Panel B: Excluding married couples in the top income quartile

\begin{tabular}{|c|c|c|c|c|}
\hline Central government & 0.20 & 0.14 & -133 & -146 \\
\hline Local government & 0.17 & 0.16 & -195 & -183 \\
\hline Private sector & 0.18 & 0.18 & -237 & -312 \\
\hline $\begin{array}{l}\text { Low-mean-and- } \\
\text { high-variance } \\
\text { industries }\end{array}$ & 0.21 & 0.21 & -439 & -529 \\
\hline - $\quad$ All other industries & 0.17 & 0.17 & -196 & -237 \\
\hline
\end{tabular}

Note: Married couples only. $N=52,928$. Renter indicates no ownership of a single-family home. $\operatorname{Cov}(p, \pi)^{h}$ is the estimated household covariance between unemployment risks and local singlefamily home prices. Sectors and industries are described in Appendix A.2. A specific industry $m$ is referred to as a low-mean-and-high-variance industry if the average value of $\operatorname{Cov}_{\mathrm{m}}(p, \pi)$ is below the average value of $\operatorname{Cov}(p, \pi)$ for all industries and $\operatorname{Var}\left(\operatorname{Cov}_{\mathrm{m}}(p, \pi)\right)$ is larger than the variance of $\operatorname{Cov}(p, \pi)$ for all industries. The following industries fulfill these two conditions (see Table 6): construction, hotels and restaurants, real estate, renting and business activities and community, social and personal service activities. 
Table 14: Empirical results of regressions on married couples' homeownership and investments in single-family homes

\begin{tabular}{|c|c|c|}
\hline & $(1)$ & (2) \\
\hline Dependent variable: & Homeowner & Home value \\
\hline$y \operatorname{Cov}(p, \pi)$ Spouse 1 & $\begin{array}{l}7.30^{* * * *} \\
{[2.793]}\end{array}$ & $\begin{array}{c}255^{* * * *} \\
{[77]}\end{array}$ \\
\hline$y \operatorname{Cov}(p, \pi)$ Spouse 2 & $\begin{array}{c}5.61 \\
{[3.897]}\end{array}$ & $\begin{array}{c}14 \\
{[76]}\end{array}$ \\
\hline \multicolumn{3}{|l|}{ Same sector } \\
\hline - Central government & $\begin{array}{c}0.02 \\
{[0.015]}\end{array}$ & $\begin{array}{c}-6,299 \\
{[39,592]}\end{array}$ \\
\hline - Local government & $\begin{array}{c}-0.01 \\
{[0.015]}\end{array}$ & $\begin{array}{l}-36,457 \\
{[28,037]}\end{array}$ \\
\hline - Private sector & $\begin{array}{c}-0.01 \\
{[0.008]}\end{array}$ & $\begin{array}{c}-14,449 \\
{[16,371]}\end{array}$ \\
\hline \multicolumn{3}{|l|}{ Same sector \& industry } \\
\hline - Central government & $\begin{array}{l}-0.04 * \\
{[0.024]}\end{array}$ & $\begin{array}{c}25,780 \\
{[49,982]}\end{array}$ \\
\hline - Local government & $\begin{array}{c}0.01 \\
{[0.012]}\end{array}$ & $\begin{array}{c}41,906 \\
{[29,693]}\end{array}$ \\
\hline - $\quad$ Private sector & $\begin{array}{c}-0.01 \\
{[0.005]}\end{array}$ & $\begin{array}{c}127,852 * * * \\
{[15,245]}\end{array}$ \\
\hline $\mathbf{Z} \times$ income controls? & Yes & No \\
\hline Adj. $R^{2} /$ Log likelihood & $-17,530$ & 0.598 \\
\hline Number of obs. & 52,665 & 45,205 \\
\hline
\end{tabular}

Note: Married couples only. Homeowner indicates ownership of a single-family home and home value is the market value of household investments in single-family homes. Robust standard errors in specification (1) and bootstrap standard errors in specification (2) are shown in square brackets. * denotes significance at $10 \%, * *$ at $5 \%$ and $* * *$ at $1 \%$. Marginal effects (multiplied by 10e5) evaluated at the mean are reported in specification (1). 263 observations are dropped in specification (1) since homeownership is perfectly predicted. $\operatorname{Cov}(p, \pi)$ is the estimated covariance between individual unemployment risks and local single-family home prices, $y$ is disposable income, spouse 1 is the spouse with the highest reported disposable income, and same industry (sector) is a variable that indicates whether both spouses work in the same industry (sector). All regressions include spouse 2's income as a percentage of spouse 1's income and, for each spouse, the $\mathbf{Z}$ vector of demographic controls (see Table 11), indicator variables for the municipality of residence, moves and civil status changes within the last five years, and interaction variables between individual income and the following variables: unemployment risk in 2003, average unemployment risk (19852003) and unemployment risk variance. In specification (2) interaction variables between municipality of residence and income and income squared are included. The explanatory variables are described in Appendix A.2. All amounts are in Swedish kronor (SEK). 
Table 15: The impact of investment horizon, education etc. on homeownership and investments in single-family homes

\begin{tabular}{|c|c|c|c|c|c|c|c|c|}
\hline \multirow[b]{2}{*}{ Dependent variable: } & (1) & (2) & (3) & (4) & (5) & (6) & (7) & (8) \\
\hline & \multicolumn{2}{|c|}{ Home value } & \multicolumn{2}{|c|}{ Home value } & \multicolumn{2}{|c|}{ Home value } & Homeowner & Home value \\
\hline \multirow{2}{*}{ Sample: } & \multirow{2}{*}{\multicolumn{2}{|c|}{ Full sample }} & \multirow{2}{*}{\multicolumn{2}{|c|}{ Homeowners }} & \multicolumn{2}{|c|}{ Single households } & \multirow{2}{*}{ Full sample } & \multirow{2}{*}{$\begin{array}{l}\text { Married } \\
\text { couples }\end{array}$} \\
\hline & & & & & Short horizon & High income & & \\
\hline Regression model: & OLS & OLS & OLS & OLS & OLS & OLS & Probit & OLS \\
\hline X variable: & $\begin{array}{c}\mathrm{X}= \\
\text { Investment } \\
\text { horizon }\end{array}$ & $\begin{array}{c}X=1 \text { if } \\
\text { move } \leq 5 \mathrm{yrs} \\
0 \text { otherwise }\end{array}$ & $\begin{array}{c}\mathrm{X}=1 \text { if debt } \\
<\mathrm{SEK} 144,000 \\
0 \text { otherwise }\end{array}$ & $\begin{array}{c}\mathrm{X}=1 \text { if } \\
\text { Stockholm, } \\
\text { 0 otherwise }\end{array}$ & $\begin{array}{c}\mathrm{X}= \\
(1-\alpha)\end{array}$ & $\begin{array}{l}X=1 \text { if low } \\
\text { education, } \\
0 \text { otherwise }\end{array}$ & $\begin{array}{c}\mathrm{X}=1 \text { if } \\
\text { Stockholm, } \\
\text { 0 otherwise }\end{array}$ & $\begin{array}{c}X=1 \text { if } \\
\text { move } \leq 5 y r s \\
0 \text { otherwise }\end{array}$ \\
\hline$y \operatorname{Cov}(p, \pi)$ & $\begin{array}{l}368 * * * \\
{[60]}\end{array}$ & $\begin{array}{l}303 * * * \\
{[36]}\end{array}$ & $\begin{array}{l}156 * * * \\
{[34]}\end{array}$ & $\begin{array}{l}115 * * * \\
{[27]}\end{array}$ & $\begin{array}{l}-235 \\
{[174]}\end{array}$ & $\begin{array}{l}513 * \\
{[295]}\end{array}$ & $\begin{array}{l}8.92 * * * \\
{[1.93]}\end{array}$ & $\begin{array}{c}199 * * \\
{[78]}\end{array}$ \\
\hline$y \operatorname{Cov}(p, \pi) \times \mathrm{X}$ & $\begin{array}{l}-10.5^{* *} \\
{[4.4]}\end{array}$ & $\begin{array}{l}174 * * \\
{[70]}\end{array}$ & $\begin{array}{c}50 \\
{[111]}\end{array}$ & $\begin{array}{c}203 \\
{[128]}\end{array}$ & $\begin{array}{l}1,083 * * \\
{[550]}\end{array}$ & $\begin{array}{l}-329 \\
{[330]}\end{array}$ & $\begin{array}{l}-2.54 \\
{[5.44]}\end{array}$ & $\begin{array}{l}463 * * \\
{[227]}\end{array}$ \\
\hline $\mathbf{Z} \times$ income controls? & No & No & No & No & No & No & Yes & No \\
\hline Adj. $R^{2} /$ Log likelihood & 0.45 & 0.43 & 0.58 & 0.58 & 0.20 & 0.18 & $-64,326$ & 0.60 \\
\hline Number of observations & 147,906 & 147,906 & 97,936 & 97,936 & 21,084 & 5,863 & 147,906 & 45,205 \\
\hline
\end{tabular}

Note: Homeowner indicates ownership of a single-family home and home value is the market value of household investments in single-family homes.

Robust standard errors are shown in square brackets. * denotes significance at $10 \%, * *$ at $5 \%$ and *** at $1 \%$. Marginal effects (multiplied by $10 \mathrm{e} 5$ ) evaluated at the mean are reported in specification (7). Individuals above the $90^{\text {th }}$ investment horizon percentile (13.9 years) in specification (5) and individuals below the $75^{\text {th }}$ income percentile (SEK 214,549) in specification (6) are excluded from the sample. Cov $(p, \pi)$ is the estimated covariance between individual unemployment risks and local single-family home prices, $y$ is household disposable income, and $(1-\alpha)$ is the share of income not covered by unemployment insurance benefits in case of unemployment. For a description of included control variables, see Tables 10 and 11 . In addition, all regressions include interaction variables between the $\mathrm{X}$ variable and all right-hand side variables. $\operatorname{Cov}(p, \pi)$ and $y$ are reported for the spouse with the highest reported disposable income of the household in specification (8). All amounts are in Swedish kronor (SEK). 
Figure 1: Population distributions of household-specific covariance estimates between unemployment risks and local home prices for same- and different-industry married couples

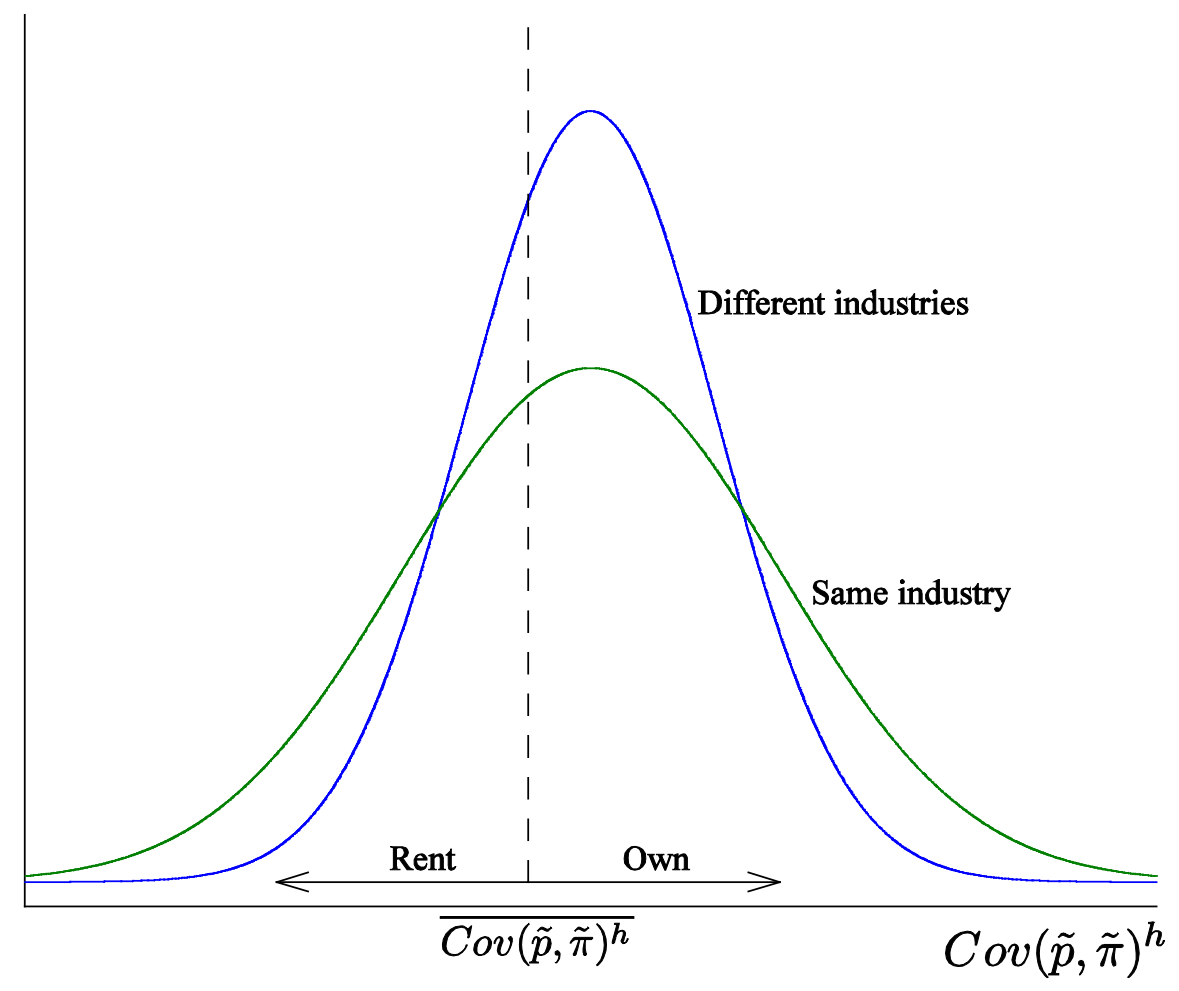

Note: $\operatorname{Cov}(\tilde{p}, \tilde{\pi})^{h}$ is the household-specific covariance between individual unemployment risks of

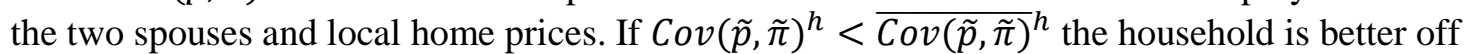
renting, and if $\operatorname{Cov}(\tilde{p}, \tilde{\pi})^{h}>\overline{\operatorname{Cov}(\tilde{p}, \tilde{\pi})^{h}}$ the household is better off owning its home. 
Figure 2: Sample distributions of covariance estimates between individual unemployment risks and local home prices at the industry level
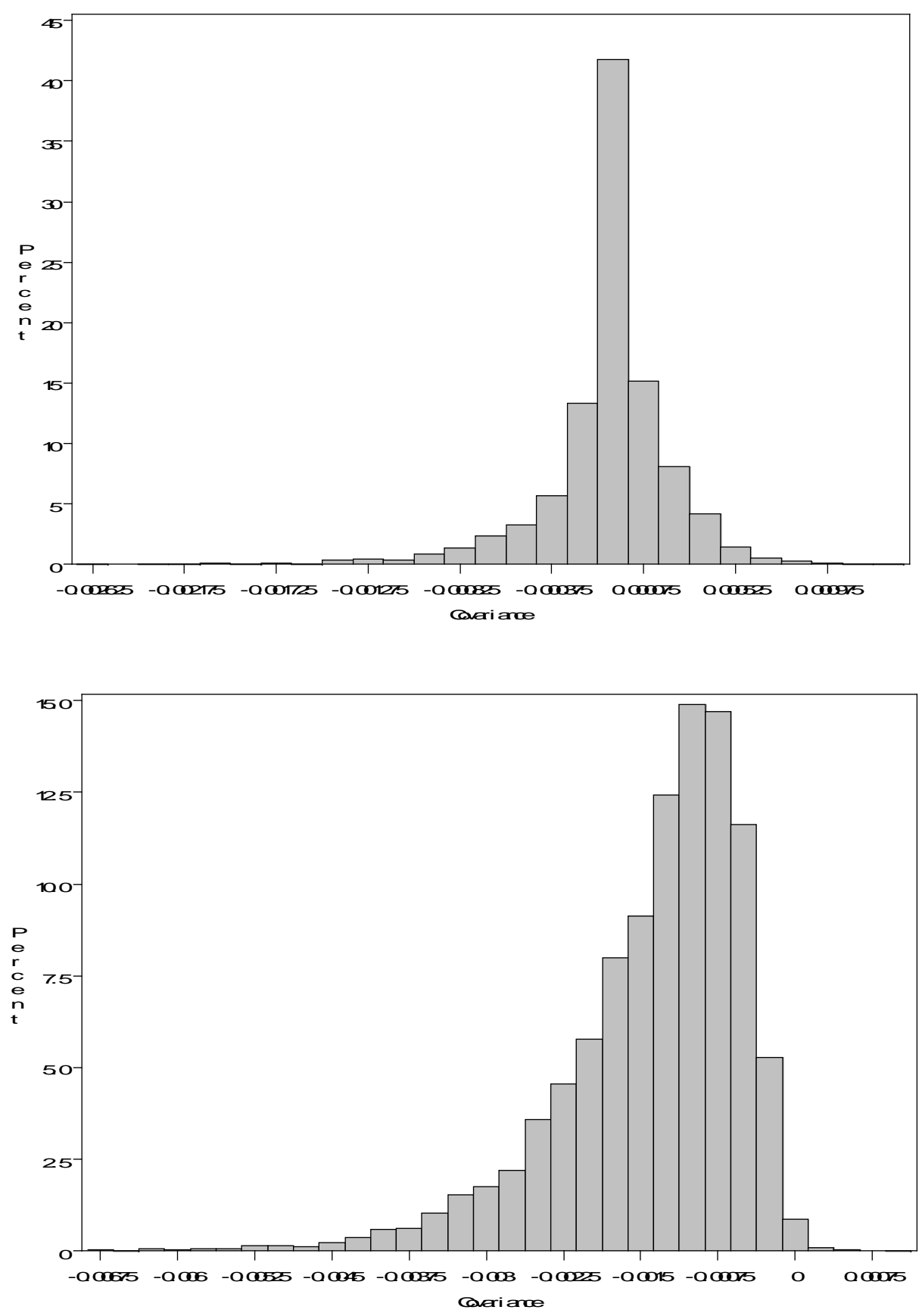

Note: The public administration and defense industry (upper) and the real estate, renting and business activities industry (lower). 


\section{Earlier Working Papers:}

For a complete list of Working Papers published by Sveriges Riksbank, see www.riksbank.se

Estimation of an Adaptive Stock Market Model with Heterogeneous Agents

2005:177

by Henrik Amilon

Some Further Evidence on Interest-Rate Smoothing: The Role of Measurement Errors in the Output Gap

2005:178

by Mikael Apel and Per Jansson

Bayesian Estimation of an Open Economy DSGE Model with Incomplete Pass-Through

2005:179

by Malin Adolfson, Stefan Laséen, Jesper Lindé and Mattias Villani

Are Constant Interest Rate Forecasts Modest Interventions? Evidence from an Estimated Open Economy

DSGE Model of the Euro Area

by Malin Adolfson, Stefan Laséen, Jesper Lindé and Mattias Villani

Inference in Vector Autoregressive Models with an Informative Prior on the Steady State

by Mattias Villani

Bank Mergers, Competition and Liquidity

by Elena Carletti, Philipp Hartmann and Giancarlo Spagnolo

Testing Near-Rationality using Detailed Survey Data

by Michael F. Bryan and Stefan Palmqvist

Exploring Interactions between Real Activity and the Financial Stance

by Tor Jacobson, Jesper Lindé and Kasper Roszbach

Two-Sided Network Effects, Bank Interchange Fees, and the Allocation of Fixed Costs by Mats $A$. Bergman

Trade Deficits in the Baltic States: How Long Will the Party Last?

by Rudolfs Bems and Kristian Jönsson

Real Exchange Rate and Consumption Fluctuations follwing Trade Liberalization

by Kristian Jönsson

Modern Forecasting Models in Action: Improving Macroeconomic Analyses at Central Banks

by Malin Adolfson, Michael K. Andersson, Jesper Lindé, Mattias Villani and Anders Vredin

Bayesian Inference of General Linear Restrictions on the Cointegration Space

2005:184

by Mattias Villani

Forecasting Performance of an Open Economy Dynamic Stochastic General Equilibrium Model

by Malin Adolfson, Stefan Laséen, Jesper Lindé and Mattias Villani

Forecast Combination and Model Averaging using Predictive Measures

by Jana Eklund and Sune Karlsson

Swedish Intervention and the Krona Float, 1993-2002

by Owen F. Humpage and Javiera Ragnartz

A Simultaneous Model of the Swedish Krona, the US Dollar and the Euro

2005:185

by Hans Lindblad and Peter Sellin

Testing Theories of Job Creation: Does Supply Create Its Own Demand?

by Mikael Carlsson, Stefan Eriksson and Nils Gottfries

Down or Out: Assessing The Welfare Costs of Household Investment Mistakes

by Laurent E. Calvet, John Y. Campbell and Paolo Sodini

Efficient Bayesian Inference for Multiple Change-Point and Mixture Innovation Models

by Paolo Giordani and Robert Kohn

Derivation and Estimation of a New Keynesian Phillips Curve in a Small Open Economy

by Karolina Holmberg

Technology Shocks and the Labour-Input Response: Evidence from Firm-Level Data

2005:187

by Mikael Carlsson and Jon Smedsaas

Monetary Policy and Staggered Wage Bargaining when Prices are Sticky

by Mikael Carlsson and Andreas Westermark

2005:188

The Swedish External Position and the Krona

2005:189

$2005: 190$

2005:191

by Philip R. Lane 
Evaluating Microfoundations for Aggregate Price Rigidities: Evidence from Matched Firm-Level Data on

Monetary Policy Trade-Offs in an Estimated Open-Economy DSGE Model

by Malin Adolfson, Stefan Laséen, Jesper Lindé and Lars E. O. Svensson

Flexible Modeling of Conditional Distributions Using Smooth Mixtures of Asymmetric

Student T Densities

by Feng Li, Mattias Villani and Robert Kohn

Forecasting Macroeconomic Time Series with Locally Adaptive Signal Extraction

Risk Premiums and Macroeconomic Dynamics in a Heterogeneous Agent Model

by Ferre De Graeve, Maarten Dossche, Marina Emiris, Henri Sneessens and Raf Wouters

Picking the Brains of MPC Members

by Mikael Apel, Carl Andreas Claussen and Petra Lennartsdotter

Involuntary Unemployment and the Business Cycle

by Lawrence J. Christiano, Mathias Trabandt and Karl Walentin

Housing collateral and the monetary transmission mechanism

by Karl Walentin and Peter Sellin

The Discursive Dilemma in Monetary Policy

by Carl Andreas Claussen and Øistein Røisland

Monetary Regime Change and Business Cycles

by Luca Sala, Ulf Söderström and Antonella Trigari

Density-Conditional Forecasts in Dynamic Multivariate Models by Michael K. Andersson, Stefan Palmqvist and Daniel F. Waggoner

Anticipated Alternative Policy-Rate Paths in Policy Simulations

The Effects of Endogenuos Firm Exit on Business Cycle Dynamics and Optimal Fiscal Policy 


\begin{tabular}{lc}
\hline The Cost of Consumer Payments in Sweden & $2012: 262$ \\
by Björn Segendorf and Thomas Jansson & $2012: 263$ \\
\hline Trade Credit and the Propagation of Corporate Failure: An Empirical Analysis & $2012: 264$ \\
by Tor Jacobson and Erik von Schedvin & $2013: 265$ \\
\hline Structural and Cyclical Forces in the Labor Market During the Great Recession: Cross-Country Evidence & \\
by Luca Sala, Ulf Söderström and AntonellaTrigari & $2013: 266$ \\
\hline Pension Wealth and Household Savings in Europe: Evidence from SHARELIFE & $2013: 267$ \\
by Rob Alessie, Viola Angelini and Peter van Santen & $2013: 268$ \\
\hline Long-Term Relationship Bargaining & $2013: 269$ \\
by Andreas Westermark & $2013: 270$ \\
\hline Using Financial Markets To Estimate the Macro Effects of Monetary Policy: An Impact-Identified FAVAR* \\
by Stefan Pitschner \\
\hline $\begin{array}{l}\text { DYNAMIC MIXTURE-OF-EXPERTS MODELS FOR LONGITUDINAL AND DISCRETE-TIME SURVIVAL DATA } \\
\text { by Matias Quiroz and Mattias Villani }\end{array}$ \\
\hline $\begin{array}{l}\text { Conditional euro area sovereign default risk } \\
\text { by André Lucas, Bernd Schwaab and Xin Zhang }\end{array}$ \\
\hline $\begin{array}{l}\text { Nominal GDP Targeting and the Zero Lower Bound: Should We Abandon Inflation Targeting?* } \\
\text { by Roberto M. Billi }\end{array}$ \\
\hline $\begin{array}{l}\text { Un-truncating VARs* } \\
\text { by Ferre De Graeve and Andreas Westermark }\end{array}$
\end{tabular}


Sveriges Riksbank

Visiting address: Brunkebergs torg 11

Mail address: se-103 37 Stockholm

Website: www.riksbank.se

SVERIGES Telephone: +46 878700 00, Fax: +46 8210531

RIKSBANK E-mail: registratorn@riksbank.se 